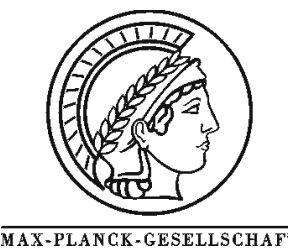

Published in: Phys. Chem. Chem. Phys. 3 (2001), 4141 -4153, published 30.08.2001

\title{
On the preparation and composition of potassium promoted iron ox- ide model catalyst films
}

\author{
Y. Joseph, G. Ketteler, C. Kuhrs, W. Ranke*, W. Weiss, R. Schlög1
}

Department of Inorganic Chemistry, Fritz-Haber-Institute of the MPG, Faradayweg 4-6, 14195 Berlin, Germany

* Corresponding author: e-mail ranke@,fhi-berlin.mpg.de, phone +49 308413 4523, fax +49 3084134401

Submitted 15 March 2001; accepted 17 July 2001

\begin{abstract}
Potassium promoted iron oxide model catalyst films were prepared by deposition of potassium onto epitaxial $\mathrm{Fe}_{3} \mathrm{O}_{4}(111)$ films at $200 \mathrm{~K}$, followed by annealing in the range 200 to $970 \mathrm{~K}$. Their formation and composition was investigated by X-ray photoelectron spectroscopy (XPS) in combination with thermal desorption spectroscopy (TDS) and thermodynamic considerations. Already at $300 \mathrm{~K}$ a solid-state reaction occurs and the iron oxide is partly reduced. Around $700 \mathrm{~K} \mathrm{a} \mathrm{KFeO}_{2}$ phase was identified which transformed at higher temperatures into $\mathrm{K}_{\mathrm{x}} \mathrm{Fe}_{22} \mathrm{O}_{34}(0.67<\mathrm{x}<4)$. This transformation started from the bulk of the film so that initially a potassium rich $\mathrm{KFeO}_{2}$ layer was formed on top of $\mathrm{K}_{\mathrm{x}} \mathrm{Fe}_{22} \mathrm{O}_{34}$. The formation of a single-crystalline $\mathrm{K}_{\mathrm{x}} \mathrm{Fe}_{22} \mathrm{O}_{34}(\mathrm{x}=0.67)$ layer, which is terminated by a submonolayer of potassium, is assumed to occur at $970 \mathrm{~K}$. For a certain potassium content, this surface develops a well ordered phase with a (2x2) superstructure. The potassium containing ph ases are not stable in water atmosphere: In $10^{-8}$ mbar $\mathrm{H}_{2} \mathrm{O}$, potassium hydroxide forms which decomposes and desorbs beyond $400-500 \mathrm{~K}$ resulting in a potassiumdepleted near-surface layer.
\end{abstract}

\section{Introduction}

Alkali metals are widely used in heterogenous catalysis as promotors $[1,2]$ and potassium is the one most often added to industrial catalysts. For example for ammonia synthesis[3], Fischer-Tropsch synthesis, water gas shift reaction or styrene production[4] iron catalysts are promoted with potassium for a better catalytic performance. The characterization of these catalysts is difficult because the variability of their composition and structure gives rise to different metastable or partly nonstoichometric phases. Therefore it is difficult to work out the promotor effects in the complex structural environment of iron oxides, hydroxides, promotor phases and possible ternary phases. Nevertheless some work on the potassium promotor action on real iron oxide catalysts for styrene synthesis was performed [5-9]. It was suggested that the catalyst in its active state is a metastable mixture of three phases namely $\mathrm{KFeO}_{2}, \mathrm{~K}_{2} \mathrm{Fe}_{22} \mathrm{O}_{34}$, and $\mathrm{Fe}_{3} \mathrm{O}_{4}$ which is formed from a mixture of $\mathrm{Fe}_{2} \mathrm{O}_{3}$ and $\mathrm{K}_{2} \mathrm{CO}_{3}$ or $\mathrm{K}_{2} \mathrm{O}$ by calcination. Under the influence of the operating atmosphere this mixture decomposes slowly into a thermodynamically stable two phase system of $\mathrm{Fe}_{3} \mathrm{O}_{4}$ and $\mathrm{KOH}$ representing the irreversibly deactivated catalyst.

In order to study the solid state reaction between potassium, oxygen, water and iron oxides, we start with well ordered iron oxide films prepared by epitaxial growth on $\mathrm{Pt}(111)$ under ultra-high vacuum (UHV) conditions. Depending on the amount of deposited iron, on oxygen partial pressure and temperature during oxidation, well ordered films of $\mathrm{FeO}(111), \mathrm{Fe}_{3} \mathrm{O}_{4}(111)$ and $\alpha-\mathrm{Fe}_{2} \mathrm{O}_{3}(0001)$ stoichiometry[10] can be prepared[11]. Their structures are well known from STM[11, 12], LEED[13] and TEM[14] investigations. In previous studies, also a well ordered potassium promoted film was produced on $\mathrm{Fe}_{3} \mathrm{O}_{4}(111)$ by adsorption of metallic potassium followed by annealing at $970 \mathrm{~K}$. It displays a $2 \times 2-$ LEED pattern with respect to the $\mathrm{Fe}_{3} \mathrm{O}_{4}(111)$ surface[15] and was termed $\mathrm{KFe}_{\mathrm{x}} \mathrm{O}_{\mathrm{y}}(111)-(2 \mathrm{x} 2)$. We will demonstrate in this paper that the bulk of this phase is most likely of the $\mathrm{K}_{\mathrm{x}} \mathrm{Fe}_{22} \mathrm{O}_{34}$ type $(0.67<\mathrm{x}<4)$ which is hexagonal. Throughout this work we will designate it simply $\mathrm{KFe}_{\mathrm{x}} \mathrm{O}_{\mathrm{y}}-(2 \mathrm{x} 2)$. The deposition and annealing of potassium on $\mathrm{Fe}_{2} \mathrm{O}_{3}(0001)$ results in a reduction to $\mathrm{Fe}_{3} \mathrm{O}_{4}(111)$ and the same $\mathrm{KFe}_{\mathrm{x}} \mathrm{O}_{\mathrm{y}}$ (2x2) surface[16].

STM investigations on this surface[17] confirmed the $(2 \times 2)$ periodicity and showed that probably two different terminations are possible but details of their structure and composition are still unknown. This question is resumed in this paper. In addition, we report on further phases containing $\mathrm{K}$, $\mathrm{Fe}, \mathrm{O}$ and possibly $\mathrm{H}$ which form during annealing of a thick potassium film deposited on $\mathrm{Fe}_{3} \mathrm{O}_{4}$. Several phases are identified combining the information from peak positions in XPS and from peak intensities. The experimental study is preceeded by a summary of the knowledge on thermodynamically stable phases containing $\mathrm{K}, \mathrm{Fe}, \mathrm{O}$ and $\mathrm{H}$, and by phase diagram calculations for the K-O system which help to identify some of the phases observed.

\section{Thermodynamic Considerations}


Known oxides and hydroxides of iron and potassium are: potassium hydroxide $\mathrm{KOH}$, potassium hyperoxide $\mathrm{KO}_{2}$, potassium peroxide $\mathrm{K}_{2} \mathrm{O}_{2}$, potassium sesquioxide $\mathrm{K}_{2} \mathrm{O}_{3}$, potassium ozonide $\mathrm{KO}_{3}$, potassium oxide $\mathrm{K}_{2} \mathrm{O}$, wustite $\mathrm{FeO}$, magnetite $\mathrm{Fe}_{3} \mathrm{O}_{4}$, hematite $\alpha-\mathrm{Fe}_{2} \mathrm{O}_{3}$, maghemite, $\boldsymbol{\gamma}-\mathrm{Fe}_{2} \mathrm{O}_{3}$, goethite $\alpha-\mathrm{FeOOH}$, akaganéite $\beta$-FeOOH (stable only in presence of halogen ions), lepidocrocite $\gamma-\mathrm{FeOOH}$, bernalite $\mathrm{Fe}(\mathrm{OH})_{3}$ and $\mathrm{Fe}(\mathrm{OH})_{2}$. At normal ambient conditions and in the presence of oxygen and water, $\mathrm{KOH}$ and $\alpha-\mathrm{Fe}_{2} \mathrm{O}_{3}$ are the only thermodynamically stable compounds. Other compounds form at different temperatures, redox environments, oxygen and water partial pressures etc. during the preparation process and may be quenched to normal ambient conditions.

Several ternary compounds containing both $\mathrm{Fe}$ and $\mathrm{K}$ are described in structural databases[18] : $\mathrm{KFeO}_{2}$ (orthorhombic, Pbca, $\mathrm{a}=5.60, \mathrm{~b}=11.25$ and $\mathrm{c}=15.90 \AA), \mathrm{K}_{3} \mathrm{FeO}_{2}$ (tetragonal, $\mathrm{P} 4{ }_{1} 22, \mathrm{a}=\mathrm{b}=6.05, \mathrm{c}=14.03 \AA$ ), $\mathrm{K}_{3} \mathrm{FeO}_{3}$ (monoclinic, $\mathrm{Cl}^{2} / \mathrm{m} 1, \mathrm{a}=7.13 . \mathrm{b}=11.12$ amd $\mathrm{c}=6.51 \AA$ ), $\mathrm{K}_{3} \mathrm{FeO}_{4}$ (orthorhombic,Pnma, $\mathrm{a}=7.70, \mathrm{~b}=9.09$ and $\mathrm{c}=$ $7.84 \AA$ ), $\mathrm{K}_{2} \mathrm{FeO}_{4}$ (orthorhombic, Pnma, $\mathrm{a}=7.70, \mathrm{~b}=5.86$ and $\mathrm{c}=10.34 \AA$ ), and $\mathrm{K}_{14}\left[\mathrm{Fe}_{4} \mathrm{O}_{13}\right]$ (monoclinic, $\mathrm{P} 2{ }_{1} / \mathrm{c}, \mathrm{a}=$ $\left.6.78, b=29.56, c=6.72, \beta=120.3^{\circ}\right)$. Further, various phases with the general composition $\mathrm{K}_{2} \mathrm{O} * \mathrm{nFe}_{2} \mathrm{O}_{3}(\mathrm{n}=2,5,6$, $7,11)$ have been described which all exhibit hexagonal symmetry $\left(\mathrm{P} 6_{3} / \mathrm{mmc}\right)$. Very likely, these compounds are mixtures of hexagonal phases with ideal compositions $\mathrm{K}_{2} \mathrm{Fe}_{4} \mathrm{O}_{7}(\mathrm{n}=2, \mathrm{a}=5.18$ and $\mathrm{c}=6.92 \AA), \mathrm{K}_{2} \mathrm{Fe}_{22} \mathrm{O}_{34}(\mathrm{n}=11$, also termed $\mathrm{K}-\beta-\mathrm{Fe}_{2} \mathrm{O}_{3}, \mathrm{a}=$ 5.92. $\mathrm{c}=23.79 \AA$ ), and $\mathrm{K}_{4} \mathrm{Fe}_{22} \mathrm{O}_{34}\left(\mathrm{~K}_{2} \mathrm{O} * 5 \mathrm{Fe}_{2} \mathrm{O}_{3} * \mathrm{FeO}\right.$, also termed $\mathrm{K}-\beta$ ' $-\mathrm{Fe}_{2} \mathrm{O}_{3}, \mathrm{a}=$ 5.92. $\mathrm{c}=35.9 \AA$ ). For the isostructural alum clays where $\mathrm{Fe}^{3+}$ is substituted by $\mathrm{Al}^{3+}$ (and lanthanoids) and $\mathrm{Fe}^{2+}$ by $\mathrm{Mg}^{2+}$, also compounds with less alkali content were reported as for instance $\mathrm{Na}_{0.16} \mathrm{Mg}_{1.08} \mathrm{Pr}_{0.88} \mathrm{Al}_{20.96} \mathrm{O}_{34}$ [19] implying that also $\beta-\mathrm{Fe}_{2} \mathrm{O}_{3}$ phases with lower alkali content may ex$\operatorname{ist}\left(\mathrm{K}_{\mathrm{x}} \mathrm{Fe}_{22} \mathrm{O}_{34}(0.67<\mathrm{x}<4)\right)$.

Thermodynamic data about the stability of these ternary potassium iron oxides are scarce. Fig. 1 shows an empirical $\mathrm{K}_{2} \mathrm{O}-\mathrm{Fe}_{2} \mathrm{O}_{3}$ "phase" diagram which was constructed using literature data. The corresponding stability regions for isostructural potassium and sodium aluminium oxides are very similar to this phase diagram although the phase boundaries are shifted to higher temperatures[20, 21]. The $\mathrm{K}_{2} \mathrm{O}$-rich part of this phase diagram is omitted for conciseness. Only a few data points at $873 \mathrm{~K}$ for $0-0.2 \mathrm{~mol} \% \mathrm{Fe}_{2} \mathrm{O}_{3}$ were reported by Ganesan and Borgstedt assigning it to a $\mathrm{K}_{3} \mathrm{FeO}_{3}$ phase[22]. The phase boundary $\mathrm{B}$ at about $1600 \mathrm{~K}$ marks the melting line of $\mathrm{KFeO}_{2}$. The phase boundary A at $\sim 0.8-0.87 \mathrm{~mol} \%$ separates the stability regions of $\alpha-\mathrm{Fe}_{2} \mathrm{O}_{3}$ (which is stable at the $\mathrm{Fe}_{2} \mathrm{O}_{3}$-rich part of the phase diagram) and $\mathrm{KFeO}_{2}$ (being stable towards the $\mathrm{KFeO}_{2}$-rich side). In both areas the potassium polyferrites $\mathrm{K}_{\mathrm{x}} \mathrm{Fe}_{22} \mathrm{O}_{34}(\mathrm{x}=2$, $\mathrm{K}-\beta$ $\mathrm{Fe}_{2} \mathrm{O}_{3}$ and $\mathrm{x}=4, \mathrm{~K}-\beta$ "' $-\mathrm{Fe}_{2} \mathrm{O}_{3}$ ) coexist with both phases over extended temperature and compositon ranges: Dvoretskii et al.[23] supposed that the formation of potassium polyferrite is a two-step process where in a first step $\mathrm{KFeO}_{2}$ is formed which in a second step reacts with hematite to potassium polyferrite.

$$
\mathrm{K}_{2} \mathrm{O}+\mathrm{Fe}_{2} \mathrm{O}_{3} \longrightarrow 2 \mathrm{KFeO}_{2} \stackrel{\mathrm{nFe}_{2} \mathrm{O}_{3}}{\longrightarrow} \mathrm{K}_{x} \mathrm{Fe}_{22} \mathrm{O}_{34}
$$

The formation of $\mathrm{KFeO}_{2}$ was found to proceed with high yield between 873-1073 $\mathrm{K}$ while the transformation of $\mathrm{KFeO}_{2}$ to $\mathrm{K}_{2} \mathrm{Fe}_{22} \mathrm{O}_{34}\left(\mathrm{~K}-\beta-\mathrm{Fe}_{2} \mathrm{O}_{3}\right)$ starts around $1023 \mathrm{~K}$. With increasing temperature Dvoretskii et al.[23] report a higher amount of potassium in the polyferrite phase due to formation of $\mathrm{K}_{4} \mathrm{Fe}_{22} \mathrm{O}_{34}\left(\mathrm{~K}-\beta\right.$ " $\left.-\mathrm{Fe}_{2} \mathrm{O}_{3}\right)$ which coexists with $\mathrm{KFeO}_{2}$ and $\mathrm{K}_{2} \mathrm{Fe}_{22} \mathrm{O}_{34}$. The higher potassium content is accomplished by a reduction of the $\alpha-\mathrm{Fe}_{2} \mathrm{O}_{3}$ under formation of $\mathrm{Fe}^{2+}$ ions which are present in $\mathrm{K}_{4} \mathrm{Fe}_{22} \mathrm{O}_{34}\left(\mathrm{~K}-\beta\right.$ ' ' $\left.-\mathrm{Fe}_{2} \mathrm{O}_{3}\right)$.
Such a reduction is favoured at high temperatures[24]. Takahashi et al. reported another phase transition at $\sim 1423 \mathrm{~K}$ beyond which $\mathrm{K}_{2} \mathrm{Fe}_{22} \mathrm{O}_{34}\left(\mathrm{~K}-\beta-\mathrm{Fe}_{2} \mathrm{O}_{3}\right)$ becomes more stable and $\mathrm{K}_{4} \mathrm{Fe}_{22} \mathrm{O}_{34}\left(\mathrm{~K}-\beta\right.$ ' ' $\left.-\mathrm{Fe}_{2} \mathrm{O}_{3}\right)$ vanishes[25]. This agrees with the observation by Rooymans et al.[26] and Dvoretskii et al.[23] who found that the potassium rich $\beta$ "'-phase $\left(\mathrm{K}_{4} \mathrm{Fe}_{22} \mathrm{O}_{34}\right)$ has a maximum of stability between 1123 and about $1273 \mathrm{~K}$. The loss of potassium at higher temperatures may simply be due to the desorption of $\mathrm{K}$ or $\mathrm{K}_{2} \mathrm{O}$ which have high vapour pressures at these temperatures[20, 27]. Dvoretskii et al.[28] determined an isothermal section of the $\mathrm{Fe}_{2} \mathrm{O}_{3}-\mathrm{Fe}_{3} \mathrm{O}_{4}-\mathrm{KFeO}_{2}$ phase diagram at $870 \mathrm{~K}$ and $1 \mathrm{mbar}$ and identified the two phases $\mathrm{K}_{\mathrm{x}} \mathrm{Fe}_{22} \mathrm{O}_{34}(\mathrm{x}=2,4)$ to be stable over the whole range of composition.

All these experimental results suggest that the ternary phases $\mathrm{KFeO}_{2}$ and $\mathrm{K}_{\mathrm{x}} \mathrm{Fe}_{22} \mathrm{O}_{34}(\mathrm{x}=2,4)$ may occur as stable phases when $\mathrm{K}_{2} \mathrm{O}$ and $\mathrm{Fe}_{2} \mathrm{O}_{3}$ are brought into contact. Similar phases are expected when potassium is deposited on $\mathrm{Fe}_{3} \mathrm{O}_{4}$ and annealed as will be done in this study.

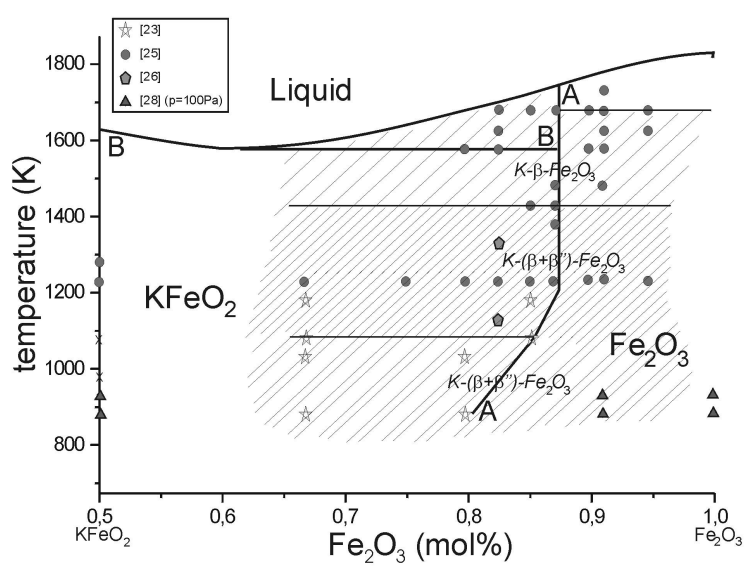

Fig. 1: $\mathrm{K}_{2} \mathrm{O}-\mathrm{Fe}_{2} \mathrm{O}_{3}$ phase diagram constructed from literature data. The phase boundary $\mathrm{B}$ is the melting line of $\mathrm{KFeO}_{2}$. The phase boundary A separates the stability regions of $\mathrm{KFeO}_{2}$ and $\alpha-\mathrm{Fe}_{2} \mathrm{O}_{3}$. On both sides of this phase boundary a mixed $\mathrm{K}_{\mathrm{x}} \mathrm{Fe}_{22} \mathrm{O}_{34}(\mathrm{x}=2,4$; $\mathrm{K}$ $\left(\beta+\beta\right.$ ') $\mathrm{Fe}_{2} \mathrm{O}_{3}$ ) phase coexists with $\alpha-\mathrm{Fe}_{2} \mathrm{O}_{3}$ or $\mathrm{KFeO}_{2}$ (shaded areas): The potassium content in this phase is represented by the density of the shading. The potassium content goes through a maximum between $\sim 1023-1423 \mathrm{~K}$ (corresponding to a $\mathrm{K}_{4} \mathrm{Fe}_{22} \mathrm{O}_{34}$ phase). Additional information is given in the text.

\subsection{Calculation of Phase Diagrams}

In order to calculate thermodynamic stability ranges for different potassium oxide phases we made use of the commercial available program EquiTherm[29]. This program calculates equilibrium compositions by minimizing the Gibbs energy at constant pressure (or volume) and constant temperature by using tabulated values for the standard enthalpy of formation, the absolute entropy, the heat capacity as well as the temperature and standard enthalpy of any phase transition of each potentially involved compound. These values are supplied by Barin[30]. Alternatively, userdefined values can be applied. The specific chemical reactions are of no importance for the calculation, since the choice of different chemical substances is equivalent with the choice of a set of independent chemical reactions. Calculations are repeated for temperatures from 100 to $1300 \mathrm{~K}$ in steps of $10 \mathrm{~K}$ and for partial pressures from $10^{-11} \mathrm{mbar}$ to $10^{-5}$ mbar in steps of every full exponent. Whenever a change in the phase composition was observed, the temperature of the phase boundary line was further refined in steps of $1 \mathrm{~K}$. By combination of several data points determined at constant pressure and temperature it is possible to construct phase diagrams with temperature and partial pressures of various 
gases like oxygen or water as variables, as has been succesfully demonstrated for the binary iron oxide phase diagram[24].

In order to model the formation of potassium oxides on iron oxide substrates we allowed the eight solid phases: iron $\left(\mathrm{Fe}^{0}\right)$, hematite $\left(\alpha-\mathrm{Fe}_{2} \mathrm{O}_{3}\right)$, magnetite $\left(\mathrm{Fe}_{3} \mathrm{O}_{4}\right)$, wustite $\left(\mathrm{Fe}_{1}\right.$. $\left.{ }_{\mathrm{x}} \mathrm{O}\right)$, potassium $\left(\mathrm{K}^{0}\right)$, potassium hyperoxide $\left(\mathrm{KO}_{2}\right)$, potassium oxide $\left(\mathrm{K}_{2} \mathrm{O}\right)$ and potassium peroxide $\left(\mathrm{K}_{2} \mathrm{O}_{2}\right)$. No miscibility was assumed because their crystal structures are quite different. Further one liquid phase containing all mentioned phases in their liquid state, and one gas phase were defined. Thermodynamic data for ternary potassium iron oxides are so scarce that it was not possible to include them into the calculation. The phase diagrams presented in fig. 2 are therefore only a superposition of both the binary phase diagrams for $\mathrm{K} / \mathrm{O}$ and $\mathrm{Fe} / \mathrm{O}$. These phase diagrams may not represent the situation at the $\mathrm{K}-\mathrm{Fe}_{3} \mathrm{O}_{4}$ interface where ternary compounds may be formed at thermodynamic equilibrium. Nevertheless, they give valuable hints which binary compounds may be expected dependent on oxygen pressures and temperatures.
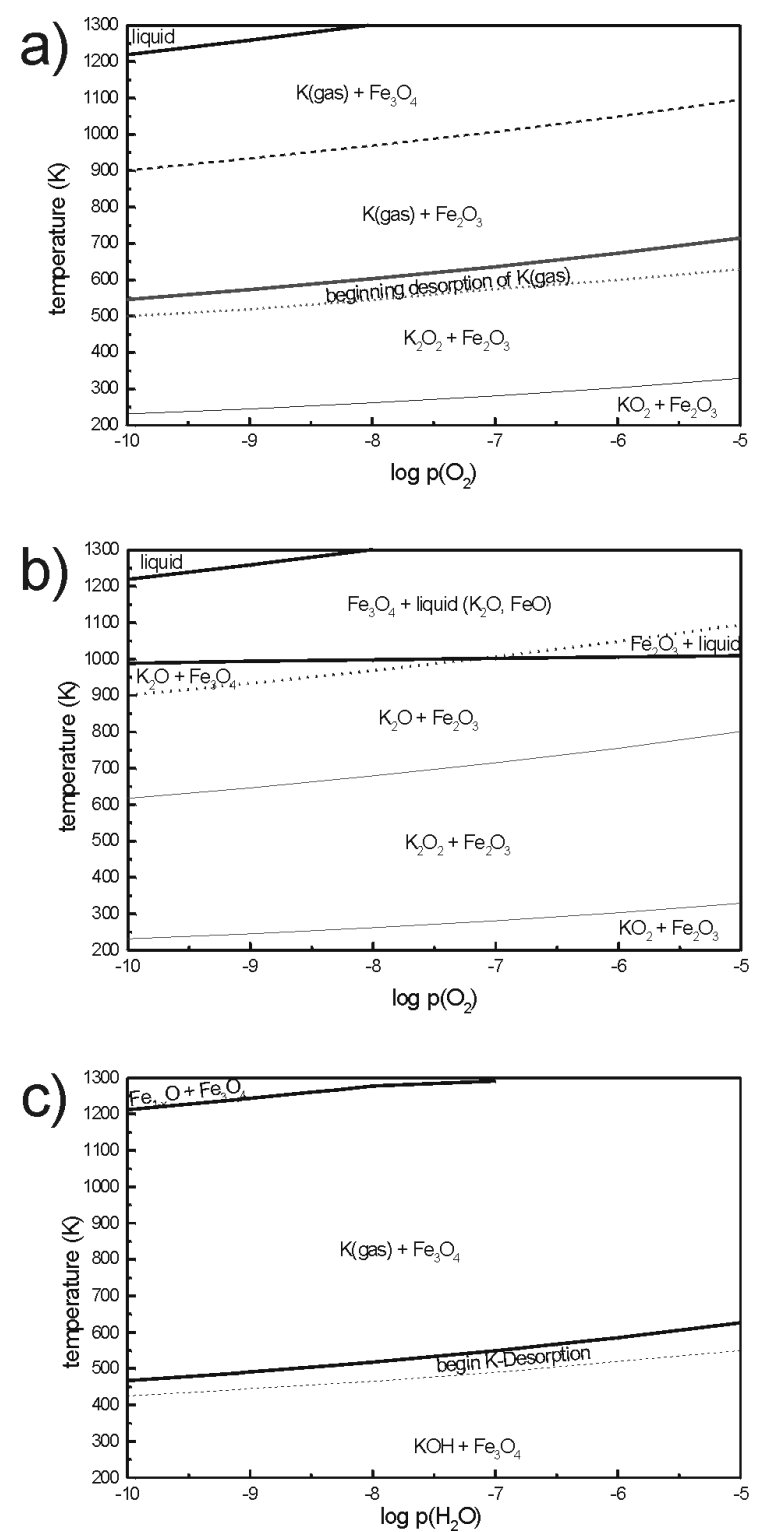

Fig. 2: (a) Calculated $\mathrm{p}\left(\mathrm{O}_{2}\right)-\mathrm{T}$ phase diagram for binary potassium and iron oxides. (b) Calculated stability regions for binary potassium and iron oxides when the desorption of potassium metal is disabled. (c) Calculated $\mathrm{p}\left(\mathrm{H}_{2} \mathrm{O}\right)$ - $\mathrm{T}$ phase diagram for binary potassium and iron oxides and hydroxides.
For the calculation of phase diagrams in dependence of the water partial pressure, we included additional solid phases for goethite $(\alpha-\mathrm{FeOOH})$, bernalite $\left(\mathrm{Fe}(\mathrm{OH})_{3}\right), \mathrm{Fe}(\mathrm{OH})_{2}$ and potassium hydroxide $(\mathrm{KOH})$. The liquid phase was completed with liquid $\mathrm{KOH}$ and water.

Fig. 2a shows the calculated p-T-phase diagram of K, Fe and $\mathrm{O}$ (ternary phases neglected). Below room temperature, potassium hyperoxide $\mathrm{KO}_{2}$ is the most stable phase whereas at higher temperatures, potassium peroxide $\mathrm{K}_{2} \mathrm{O}_{2}$ forms. The dotted boundary line ranging from $500 \mathrm{~K}$ at $10^{-10} \mathrm{mbar} \mathrm{O}_{2}$ to $630 \mathrm{~K}$ at $10^{-5}$ mbar marks the beginning desorption of metallic potassium gas. Approximately $50-80 \mathrm{~K}$ higher, all potassium has evaporated and hematite is the only remaining solid phase. The conversion of hematite to magnetite appears at much higher temperatures $\left(900 \mathrm{~K}\right.$ at $10^{-10} \mathrm{mbar}$ to $1100 \mathrm{~K}$ at $10^{-5} \mathrm{mbar}$ ). As expected, this phase boundary agrees exactly with the boundary curve calculated for the binary $\mathrm{Fe}-\mathrm{O}$ phase diagram[24].

The interface region in a real system of a potassium layer on magnetite is spatially isolated from the gas phase and potassium from this region can not immediately desorb. The phase composition may be better described by a phase diagram where the complete desorption of potassium is disabled. Such a phase diagram is shown in fig. $2 \mathrm{~b}$. Below $500 \mathrm{~K}$ and above $1000 \mathrm{~K}$, this phase diagram is identical to the one shown in fig. 2a but beyond a boundary line ranging from $617 \mathrm{~K}$ at $10^{-10}$ mbar to $801 \mathrm{~K}$ at $10^{-5}$ mbar potassium oxide $\mathrm{K}_{2} \mathrm{O}$ becomes the most stable $\mathrm{K}$-containing phase. The potassium oxide (mixed with wustite $\mathrm{FeO}$ ) melts around $1000 \mathrm{~K}$.

Fig. 2c shows stability regions in dependence of the water partial pressure. Below a phase boundary ranging from $447 \mathrm{~K}$ at $10^{-11}$ mbar to $626 \mathrm{~K}$ at $10^{-5} \mathrm{mbar}, \mathrm{KOH}$ is formed while beyond this phase boundary $\mathrm{KOH}$ decomposes and potassium desorbs into the gas phase.

\section{Experimental and Data Evaluation}

\subsection{Experimental Equipment}

Two different UHV chambers with base pressures of $1 \times 10^{-}$

${ }^{10}$ mbar were used. The sample holder and the chamber where the thermal desorption spectroscopic measurements (TDS) were performed were described before[31]. Besides a quadrupole mass spectrometer it contained a cylindrical mirror analyser (CMA) for Auger electron spectroscopy (AES). After potassium deposition at $100 \mathrm{~K}$ the TD spectra were taken using a heating rate of $5 \mathrm{~K} / \mathrm{s}$. The XPS chamber was equipped with a PHI double-pass CMA and a X-ray source (VSW) for photoemission measurements. All XP spectra were measured with $\mathrm{Mg} \mathrm{K} \alpha$ radiation ( $\mathrm{h} v=1253.4$ $\mathrm{eV}$ ) at a pass energy of $50 \mathrm{eV}$. The binding energies were calibrated using the signals from the Pt single crystal substrate $\left(\mathrm{Pt} 4 \mathrm{f}_{7 / 2}, \mathrm{BE}=71.2 \mathrm{eV}\right)$ and the $\mathrm{Cu}$ sample holder $(\mathrm{Cu}$ $3 p, \mathrm{BE}=75.1 \mathrm{eV}, \mathrm{Cu} 2 \mathrm{p}_{3 / 2}, \mathrm{BE}=962.7 \mathrm{eV}$ ) [32]. Both chambers were equipped with LEED optics for the control of the surface crystallinity and an $\mathrm{Ar}^{+}$sputter gun, an iron evaporator, a potassium (SAES) getter source and a gas inlet system as well as heating and cooling facilities for sample preparation.

The iron oxide surfaces were prepared on a clean $\operatorname{Pt}(111)$ single crystal by iron evaporation and subsequent oxidation as described before[12,33-34]. The $\mathrm{KFe}_{\mathrm{x}} \mathrm{O}_{\mathrm{y}}-(2 \mathrm{x} 2)$ film was prepared by evaporation of metallic potassium on a $\mathrm{Fe}_{3} \mathrm{O}_{4}(111)$ film and subsequent annealing to $970 \mathrm{~K}$ as described in ref.[15].

All samples were checked for contaminants (especially carbon) by XPS or AES. For the annealing experiments a large amount $(>20 \mathrm{ML})$ of potassium was deposited on the $\mathrm{KFe}_{\mathrm{x}} \mathrm{O}_{\mathrm{y}}-(2 \mathrm{x} 2)$ structure at $200 \mathrm{~K}$. Then XP spectra were collected after annealing for $1 \mathrm{~min}$ at stepwise increasing 
temperatures. The experiments under water atmosphere were performed during a continuous inlet of $10^{-8}$ mbar of triply destilled degassed water. The annealing times in these experiments were 2 minutes. The Fe $2 p$ region and $\mathrm{O} 1 \mathrm{~s}, \mathrm{C} 1 \mathrm{~s}$, $\mathrm{K} 2 \mathrm{p}$ and the $\mathrm{K}_{\mathrm{LMM}}$ peaks were measured. The shape of the $\mathrm{K}_{\mathrm{LMM}}$ spectra is not discussed in this work but their intensity is determined and used in the composition analysis. Carbon contamination was never observed during the measurements. From the O 1 s and K $2 p$ spectra a Shirley background was subtracted and the remaining signal fitted by Gauss-Lorentz mixed curves (Voigt profiles). The Gauss-Lorentz ratio was always 0.25 and the full width at half maximum $2.21 \mathrm{eV}$. Both values were determined by fitting the O1s signal of the clean $\mathrm{Fe}_{3} \mathrm{O}_{4}(111)$ surface. The Fe $2 p$ region of selected spectra was fitted by weighted sums of the reference spectra of metallic iron, $\mathrm{FeO}(111)$ and $\alpha-\mathrm{Fe}_{2} \mathrm{O}_{3}(0001)$ representing $\mathrm{Fe}^{0}, \mathrm{Fe}^{2+}$ and $\mathrm{Fe}^{3+}$ in a similar way as in ref. [35].

\subsection{Quantitative analysis using XPS intensities}

The intensities of XPS peaks are used to estimate the depth dependent composition of the samples. Peak intensities were obtained by integration after a simple linear background subtraction which turned out to be most reliable. It was essential that the integration boundaries and the kind of background subtraction was the same for all measurements so that possible errors are expected to be proportional to the peak area and do thus not affect the quantitative analysis. The electron mean free path $\lambda_{x}$ of an electron $\mathrm{x}$ with the kinetic energy $E_{x}$

$$
\lambda_{x}=B \sqrt{ } E_{x}, \quad E_{x}>150 \mathrm{eV}
$$

enters into this analysis. Although the value of the constant $B$ may depend on the material, the squareroot-dependence on $E_{x}$ seems established beyond $150 \mathrm{eV}[36]$. We use the value $B=0.54$ as given for elements in [36]. The influence of the variation of $B$ will be discussed below.

In our experimental setup it was not possible to vary the information depth by measuring under different escape angles. At least in the case of potassium, however, two peaks exist in the spectra which have strongly different escape depths. The electron mean free path for the $\mathrm{K}_{\mathrm{LMM}}$-Auger peak is about half that of the K $2 p$ photoelectron peak (see table 1). The $\mathrm{K}_{\mathrm{LMM}}$-peak is therefore more surface sensitive than the $\mathrm{K} 2 \mathrm{p}$ peak. A first conclusion on the depth distribution of potassium can be drawn from a comparison of the intensity ratio $J(K 2 p) / J\left(K_{L M M}\right)$ of the sample under investigation with that of a reference sample with homogeneous potassium distribution (as e.g. a thick metallic potassium). If $\mathrm{J}(\mathrm{K} 2 \mathrm{p}) / \mathrm{J}\left(\mathrm{K}_{\mathrm{LMM}}\right)$ is larger (smaller) than the reference value, the near surface region is potassium depleted (enriched) compared to the bulk. This does not depend on the absolute potassium concentration.

\begin{tabular}{|l|c|c|c|c|}
\hline Peak & K 2p & $\mathrm{K}_{\mathrm{LMM}}$ & Fe 2p & O 1s \\
\hline $\boldsymbol{E}_{\boldsymbol{x}}(\mathbf{e V})$ & 954 & 245 & 530 & 719 \\
\hline$\lambda_{\mathbf{x}}(\boldsymbol{\AA})$ & 17.6 & 8.9 & 13.1 & 15.3 \\
\hline $\boldsymbol{l}_{\boldsymbol{x}}(\boldsymbol{\AA})$ & 13.1 & 6.6 & 9.7 & 11.4 \\
\hline $\boldsymbol{V}_{\boldsymbol{x}}\left(\AA^{3}\right)$ & \multicolumn{2}{|c|}{30} & 7 & 12 \\
\hline
\end{tabular}

Table 1: The studied XPS peaks, their approximate kinetic energies $E_{x}$, electron mean free paths $\lambda_{\mathrm{x}}$, escape depth values $l_{x}$ and atomic volumes $V_{x}$.

In order to quantify atomic concentrations, we use a „discrete layer model" (DLM). As shown schematically for the compound $\mathrm{K}_{2} \mathrm{Fe}_{22} \mathrm{O}_{34}$ in fig. 3a, the sample is divided into a surface region of thickness $z_{s}$, the composition of which one wants to vary, and the bulk. Both consist of atomic layers from which the signal is summed up, each attenuated by the layers lying above. The intensity of peak $x$ is then given by

$$
J_{x}=J_{x, 0} A\left[J_{x, s}+J_{x, b} e^{-z_{s} / l_{x}}\right]
$$

Here, $J_{x, 0}$ is the reference intensity or the sensitivity factor for peak $x$ and $A$ is the area from which the signal comes. $\left(J_{x, 0} A\right)$ has to be determined as described below. $J_{x, s}$ is the contribution from the surface layer and $J_{x, b}$ is the bulk contribution which is attenuated by the surface layer. The attenuation factor contains the thickness $z_{s}$ of the surface layer and the escape depth $l_{x}$ given by

$$
l_{x}=\lambda_{x} \cos \alpha .
$$

Here, $\alpha$ is the escape angle of the analysed electrons. Its mean value is $42^{\circ}$ when using a CMA as in our case. The signal from the surface layer is given by

$$
J_{x, s}=\sum_{i=0}^{n_{s}-1}\left(\sigma_{x, i} e^{-z_{i} / l_{x}}\right)
$$

with $n_{s}$ the number of atomic layers and $\sigma_{x, i}$ the number of atoms $x$ per $\mathrm{cm}^{2}$ in the layer $\mathrm{i}$ at depth $z_{i}$.
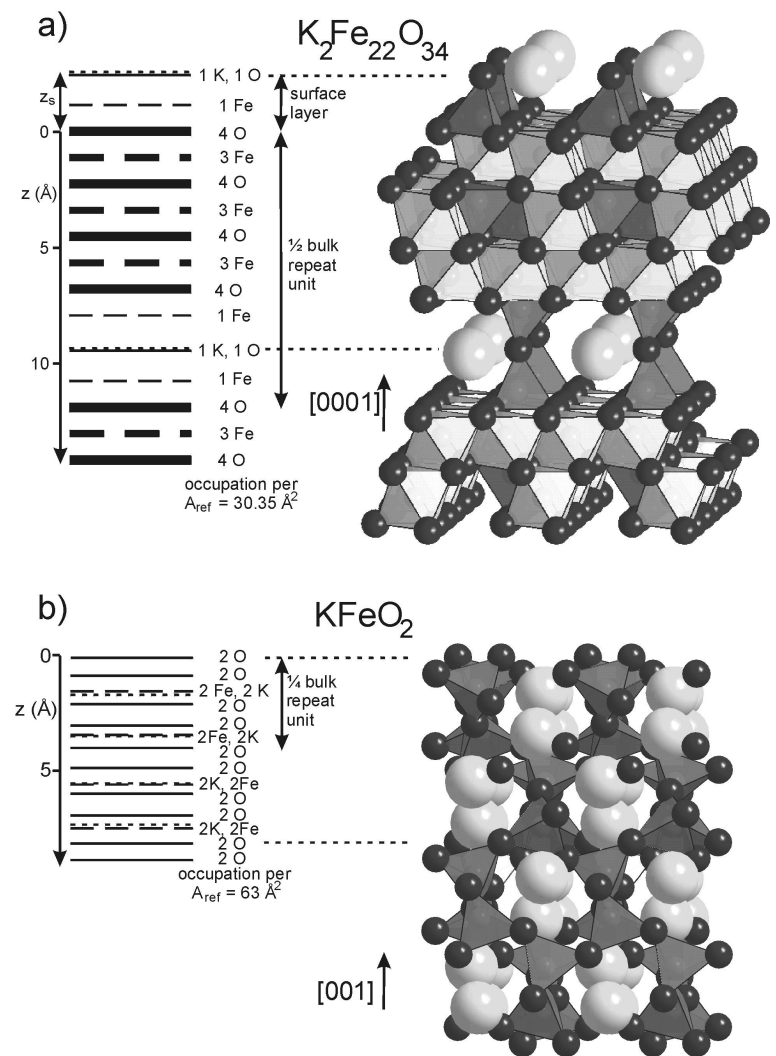

Fig. 3: Structure models and layer arrangement for the ternary compounds $\mathrm{K}_{2} \mathrm{Fe}_{22} \mathrm{O}_{34}$ (a) and $\mathrm{KFeO}_{2}$ (b). Large grey balls represent $\mathrm{K}$, small dark balls represent $\mathrm{O}$. The $\mathrm{Fe}$ atoms are located in the center of the octahedra and tetrahedra. In the layer structures, full, broken and dotted lines represent layers containing $\mathrm{O}, \mathrm{Fe}$ and $\mathrm{K}$, respectively. The line widths are proportional to the atomic densities. The layer occupations per surface unit cell area $A_{\text {ref }}$ are indicated. $\mathrm{K}_{2} \mathrm{Fe}_{22} \mathrm{O}_{34}$ has a hexagonal layer structure. Along [0001] it is built up from iron-oxygen blocks separated by $\mathrm{Fe}-\mathrm{KO}-\mathrm{Fe}$ layers. The iron-oxygen blocks have the inverse spinel structure of magnetite $\mathrm{Fe}_{3} \mathrm{O}_{4}$ and consist of four hexagonally close packed oxygen layers with one Kagomé-, one mixed-trigonal and another Kagomé-iron layer between them[24]. The unit cell in the (0001) surface is almost exactly the same as for $\mathrm{Fe}_{3} \mathrm{O}_{4}(111)$ and epitaxial growth should be easy. Along [0001], the bulk unit cell consists of two identical but laterally shifted layer blocks. The layer repeat unit is therefore $1 / 2$ of the bulk repeat unit. $\mathrm{KFeO}_{2}$ is tetragonal and does not fit with the lattice of $\mathrm{Fe}_{3} \mathrm{O}_{4}$. It has no marked layer structure and $\mathrm{K}, \mathrm{Fe}$ and $\mathrm{O}$ are almost uniformly distributed. Along the shown [001] direction, the unit cell consists of four non-identical but very similar laterally shifted groups of layers. The first one of them is marked as $1 / 4$ bulk repeat unit. 
The bulk consists of repeat units, each consisting of $n_{p}$ layers. The contribution of the first repeat unit is summed up in a similar way as for the surface layer.

$$
J_{x, p}=\sum_{i=0}^{n_{p}-1}\left(\sigma_{x, i} e^{-z_{i} / l_{x}}\right)
$$

The contribution of the second repeat unit is attenuated by the first one etc. . All contributions form an infinite row which can be summed up:

$$
J_{x, b}=\sum_{n=0}^{\infty} J_{x, p} e^{-n z_{p} / l_{x}}=J_{x, p}\left(1-e^{-z_{p} / l_{x}}\right)^{-1}
$$

In order to determine the surface layer thickness $z_{s}$ in equ. (2), the atomic volumes $V_{x}$ of all atoms in the surface layer per reference area $A_{r e f}$ (e.g. unit cell area) are summed up and divided by $A_{r e f}$. From the crystal structures and atomic densities of compounds like $\mathrm{K}_{2} \mathrm{O}, \mathrm{K}_{2} \mathrm{O}_{2}, \mathrm{KFeO}_{2}$ these atomic volumes can be estimated. It turned out that these volume values were between those expected from metallic or covalent and ionic radii. The used values are included in table 1. The values $\left(J_{x, 0} A\right)$ were determined from reference spectra of samples of known composition and structure, namely a thick metallic potassium layer and a well ordered epitaxial $\mathrm{Fe}_{3} \mathrm{O}_{4}(111)$ film which, according to previous investigations [12] is terminated by an iron layer with a density corresponding to $1 / 4$ of the hexagonal close packed oxygen layers. The experimentally determined integrated reference intensities $J_{x}$ were introduced in equ. (2) and the $\left(J_{x, 0} A\right)$ values were determined. In this way, all errors introduced by the use of external sensitivity factors were avoided.

The factor $B$ in equ. (1) which determines the absolute values of the electron mean free path $\lambda_{\mathrm{x}}$ and thus the escape depth $l_{\mathrm{x}}$ is not well established. We have checked its influence on the quantitative analysis. The value of $l_{\mathrm{x}}$ enters into equ. (2) and into the summations $(4,5,6)$ but also into the determination of the values for $\left(J_{x, 0} A\right)$ from the same equations. As a consequence, the intensities $J_{x}$ do not depend on $B$ for materials with homogeneous distribution of the elements. A significant dependence of the $J_{x}$-values on $B$ occurs for layered structures if the layer distance exceeds the escape depth $l_{\mathrm{x}}$. But even for $\mathrm{K}_{2} \mathrm{Fe}_{22} \mathrm{O}_{34}$ with a K-layer distance of $11.9 \AA$ (fig. 3a), the influence is weak. In any case it is reliably possible to distinguish beween phases with clearly different composition like $\mathrm{Fe}_{3} \mathrm{O}_{4}, \mathrm{~K}_{2} \mathrm{Fe}_{22} \mathrm{O}_{34}, \mathrm{KFeO}_{2}$ and $\mathrm{K}$ oxides.

\section{Results and Discussion}

\subsection{Preparation and Characterisation of the $\mathrm{KFe}_{x} \underline{O}_{y}$ (2x2) phase}

As reference spectra, fig. 4 shows Fe $2 p$ XPS spectra of clean iron and of the three clean iron oxide films of different stoichiometry. The corresponding LEED patterns of the oxides are inserted. As discussed before[11], the FeO film investigated is only $1 \mathrm{Fe}-\mathrm{O}$ bilayer thick. Therefore the LEED pattern contains also spots from the $\mathrm{Pt}(111)$ substrate and multiple scattering spots. Nevertheless, the binding energy and the satellite structure corresponds clearly to $\mathrm{Fe}^{2+}$ in $\mathrm{FeO}[37]$. Also the other spectra illustrate the different binding energies and the different satellite structure for iron in its different oxidation states in good agreement with data from the literature $[9,10,35,37,38]$.

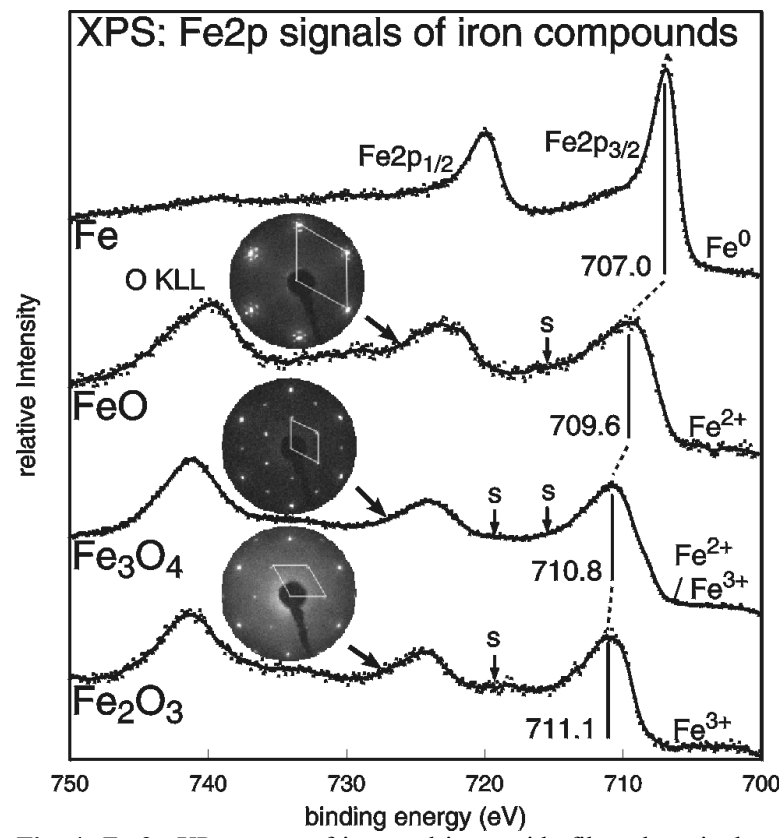

Fig. 4: Fe 2p XP spectra of iron and iron oxide films deposited on $\mathrm{Pt}(111)$. The binding energies of the $\mathrm{Fe} 2 \mathrm{p} 3 / 2$ signals and the LEED pattern of the oxides are given.

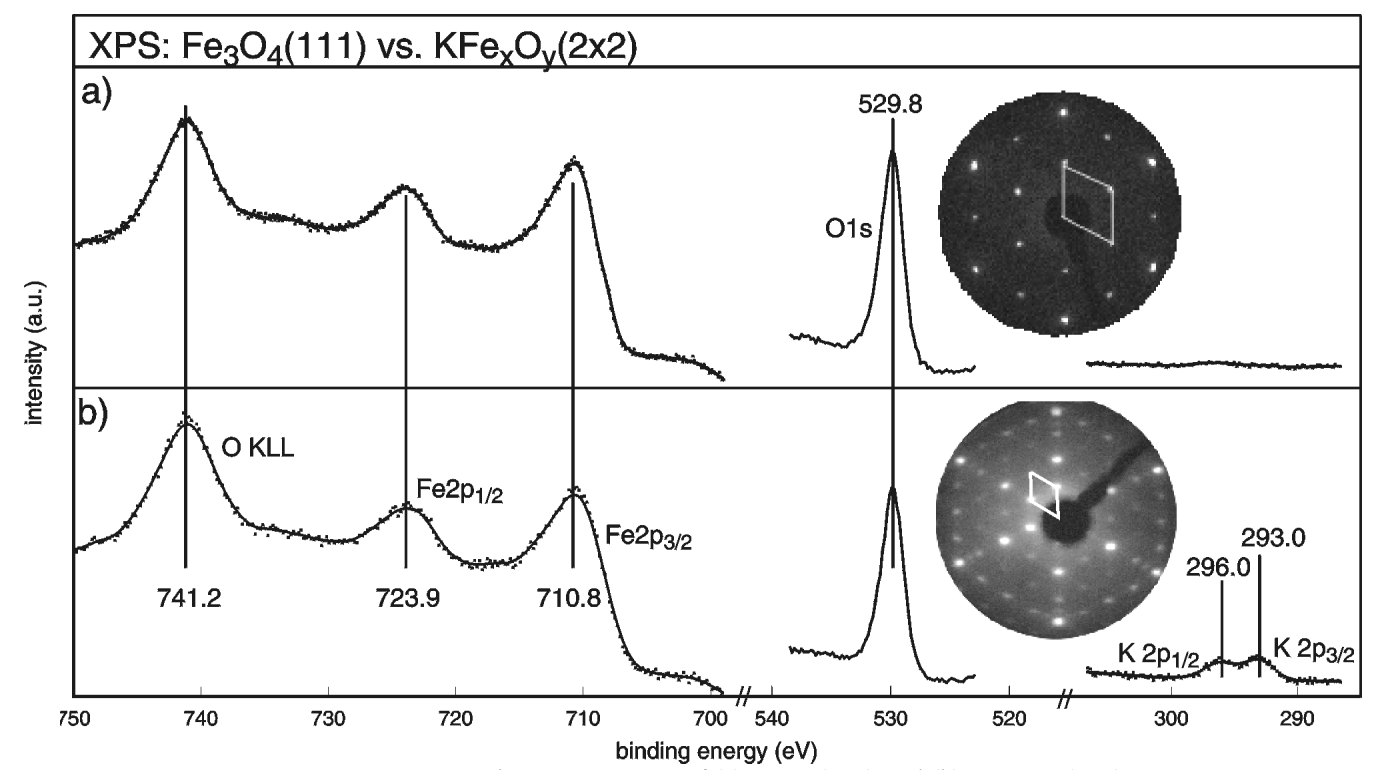

Fig. 5: XP spectra and LEED patterns of (a) $\mathrm{Fe}_{3} \mathrm{O}_{4}(111)$ and (b) $\mathrm{KFe}_{\mathrm{x}} \mathrm{O}_{\mathrm{y}}-(2 \mathrm{x} 2)$. 
The $\mathrm{KFe}_{\mathrm{x}} \mathrm{O}_{\mathrm{y}}-(2 \mathrm{x} 2)$ phase is prepared by deposition of potassium on a $\mathrm{Fe}_{3} \mathrm{O}_{4}$ film and annealing to $970 \mathrm{~K}$. In fig. 5 the core level photoelectron spectra of $\mathrm{Fe}_{3} \mathrm{O}_{4}(111)$ are compared to those of the $\mathrm{KFe}_{\mathrm{x}} \mathrm{O}_{\mathrm{y}}-(2 \mathrm{x} 2)$ phase. Both the binding energies of the $\mathrm{Fe} 2 \mathrm{p}$ and $\mathrm{O} 1 \mathrm{~s}$ signals and the peak shapes are identical suggesting that the bulk of $\mathrm{KFe}_{\mathrm{x}} \mathrm{O}_{\mathrm{y}}$ is essentially $\mathrm{Fe}_{3} \mathrm{O}_{4}$-like. The signal intensities of $\mathrm{Fe}$ and $\mathrm{O}$ are only slightly smaller in the $\mathrm{KFe}_{\mathrm{x}} \mathrm{O}_{\mathrm{y}}-(2 \times 2)$ phase and the amount of potassium is quite small when compared with the signal of a thick potassium layer (compare the lower two curves in fig. 9a, b below). Although the surface concentration of potassium after annealing is low, it is necessary to deposit a considerable higher amount before annealing in order to obtain the $\mathrm{KFe}_{\mathrm{x}} \mathrm{O}_{\mathrm{y}}-(2 \mathrm{x} 2)$ phase. It is therefore likely that the well ordered surface structure forms only after diffusion and possibly reaction of the potassium in the bulk. This will be investigated and considered more quantitatively in section 4.2 and 4.3. The separation of the peaks corresponding to $K 2 p_{3 / 2}$ and $K 2 p_{1 / 2}$ is $3.0 \mathrm{eV}$ and thus clearly larger then the spin-orbit split (2.77[32]). It is likely that this is the result of overlapping contributions from two different potassium species of similar concentration.

\subsection{Surface Phases during annealing}

To investigate the diffusion of potassium in the bulk and reaction with the iron oxide we deposited different amounts of potassium on an initially clean $\mathrm{Fe}_{3} \mathrm{O}_{4}(111)$ substrate. Fig. 6a presents the TD traces from 100 to $700 \mathrm{~K}$ for potassium deposited at a sample temperature of $100 \mathrm{~K}$. After the first deposition, a small peak appears near $400 \mathrm{~K}$ which we ascribe to a chemisorbed species[16]. Already after the second exposure it has developed into a broad signal extending up to $550 \mathrm{~K}$ indicating stronger bonding of potassium. This shows that the sample surface must have changed under the influence of the first K-deposition and annealing to $700 \mathrm{~K}$. Upon further deposition the chemisorption peak develops into a peak at $430 \mathrm{~K}$ and a shoulder near $520 \mathrm{~K}$. Simultaneously, a peak with a common leading edge indicating zero order desorption develops with its maximum shifting from initially $290 \mathrm{~K}$ to about $360 \mathrm{~K}$ at high coverage. In agreement with the assignment by other authors $[39,40]$ we assign it to K-multilayer desorption. The total area under the desorption traces is plotted in fig. 6b. Initially it increases only very slightly but after an exposure of $150 \mathrm{~s}$ the slope increases suddenly. A very similar behaviour was observed for potassium on $\mathrm{MgO}(100)[41]$. It was ascribed to a change of the sticking coefficient when the first layer of strongly polarized chemisorbed potassium with repulsive lateral interaction is completed and the formation of a metallic multilayer starts. Therefore we have measured the dependence of peak intensities on deposition time at $200 \mathrm{~K}$ by XPS which gives the amount of potassium being on the surface in contrast to TDS which gives the amount going off. At $200 \mathrm{~K}$ the potassium diffusion into the oxide substrate still is negligibly small. Both the $\mathrm{K}_{\mathrm{LMM}}$ and $\mathrm{K} 2 \mathrm{p}$ peaks increase and the $\mathrm{Fe} 2 \mathrm{p}$ and $\mathrm{O}$ 1s peaks decrease without break at the coverage where multilayer adsorption begins. A coverage dependent sticking coefficient can therefore be ruled out as reason for the behaviour shown in fig. $6 \mathrm{~b}$. Even after annealing of a several ML thick K-layer to $970 \mathrm{~K}$, additional $\mathrm{K}$ deposition at $200 \mathrm{~K}$ resulted in the same sticking coefficient. The XPS measurements showed further that after annealing to $700 \mathrm{~K}$ (the maximum temperature between TDS runs in fig. 6a) an appreciable amount of $\mathrm{K}$ still was within the analysis depth of XPS which is in agreement with AES measurements published before[15]. The amount desorbing from the chemisorption peak alone without multilayer peak is also given in fig. $6 \mathrm{~b}$. If we assume that its saturation value corresponds roughly to $1 \mathrm{ML}$ we obtain an approximate calibration of the ordinate scale. We conclude from the steeply increasing part of the total amount curve that an evaporation time of $30 \mathrm{~s}$ corresponds roughly to $1 \mathrm{ML}$.
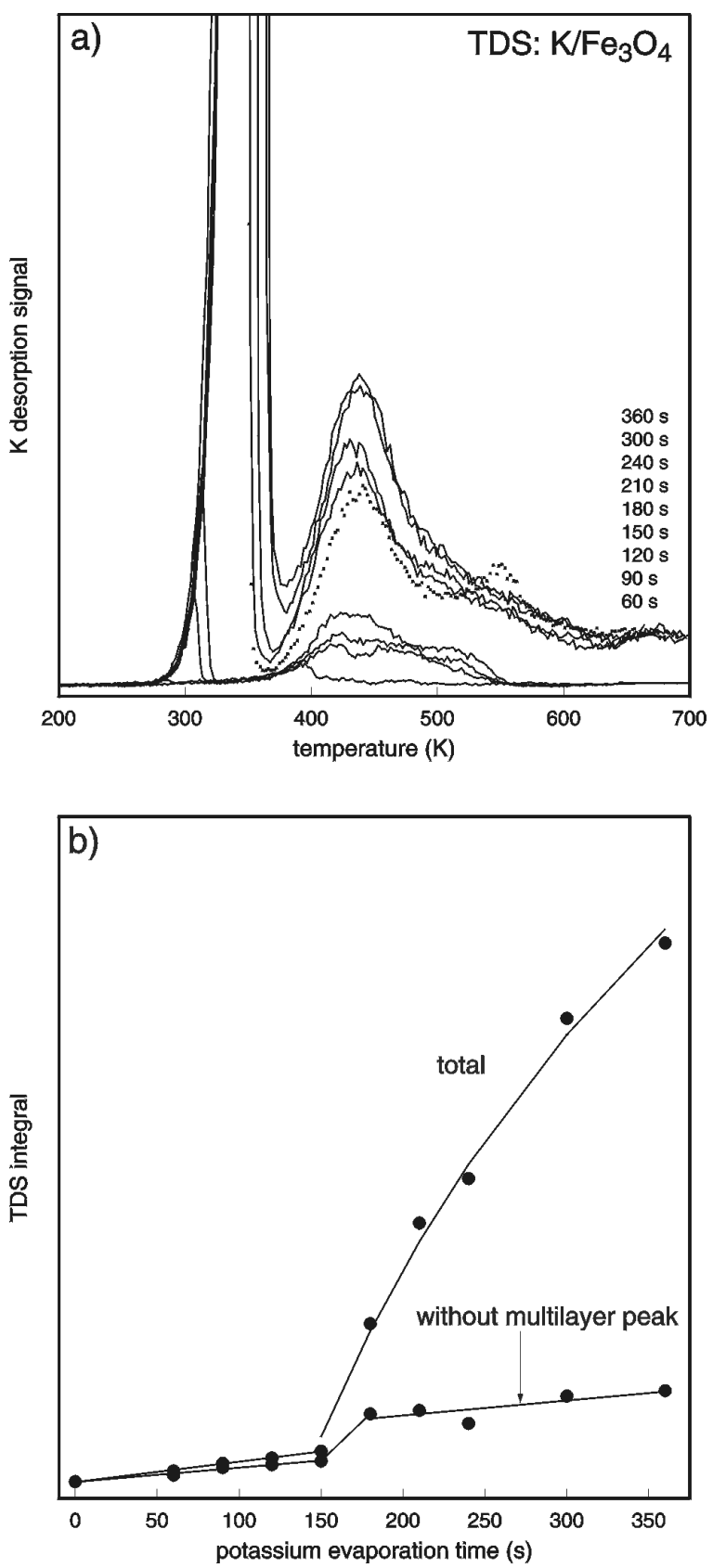

Fig. 6: (a) Thermal desorption traces of potassium deposited on initially clean $\mathrm{Fe}_{3} \mathrm{O}_{4}(111)$ at $100 \mathrm{~K}$. The deposition times are indicated (b) Dependence of the total area under the TD traces and area under the chemisorption peak (380-700 K) without multilayer peak on deposition time.

Since the sticking coefficient for $\mathrm{K}$ was found here to be independent of coverage, we conclude that the main part of potassium deposited within the first 150 s, i.e. roughly 5 $\mathrm{ML}$, must have been incorporated into the $\mathrm{Fe}_{3} \mathrm{O}_{4}$ substrate during the temperature ramps. Within this period, the desorption both from the multilayer and the chemisorbed species represents only a minority reaction channel. We can further conclude that the incorporation must have occurred already below the onset of multilayer desorption at $280 \mathrm{~K}$. Only after saturation of the substrate, additionally deposited potassium is desorbed in the TD runs. The composition of this saturated substrate phase will be identified as $\mathrm{KFeO}_{2}$ in section 4.3 . 
The first TD scan in fig. 6 a after saturation of the substrate (deposition time $180 \mathrm{~s}$, dotted) displays a sharp extra peak at $550 \mathrm{~K}$ which does not appear again after additional depositions. It appears also when large depositions are made in one run (e.g. $300 \mathrm{~s}$ ) but also then only once. It appears at a position typical for $\mathrm{K}$ desorption from elemental iron[39]. This is a hint that the penetration of potassium into the substrate bulk may be related with a chemical reaction namely the reduction of oxidic iron to $\mathrm{Fe}^{0}$.

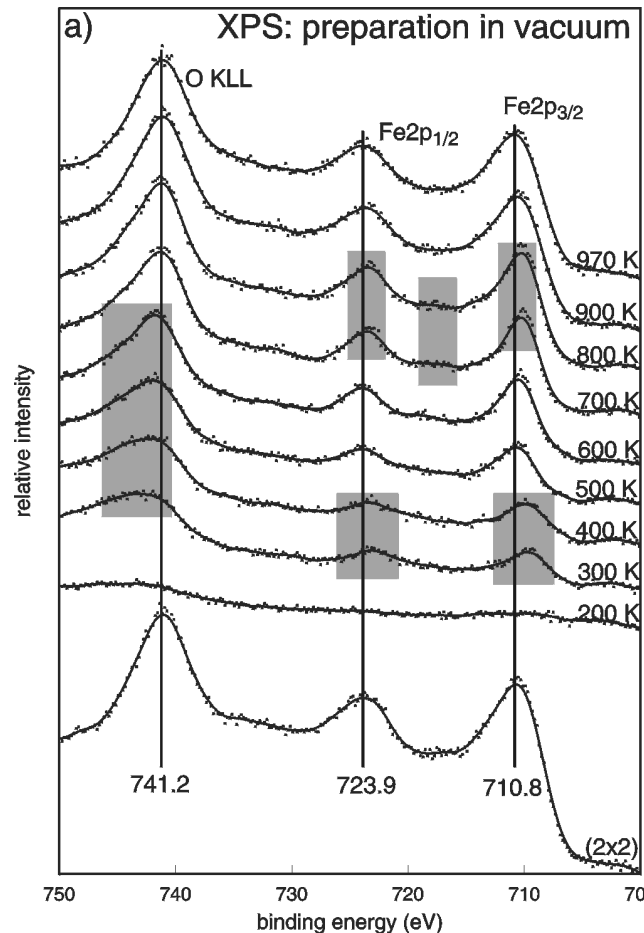

Fig. 7: $\mathrm{Fe} 2 \mathrm{p} \mathrm{XP}$ and $\mathrm{O}_{\mathrm{KLL}}$ spectra $(\mathrm{h} v=1253.6 \mathrm{eV})$ of $\mathrm{KFe}_{\mathrm{x}} \mathrm{O}_{\mathrm{y}}-(2 \mathrm{x} 2)$, after deposition of a thick potassium layer at $200 \mathrm{~K}$ and after annealing to the indicated temperatures (a) in vacuum, (b) in $1 \times 10^{-8} \mathrm{mbar} \mathrm{H}_{2} \mathrm{O}$. The shaded areas mark shifted peaks and satellite features discussed in the text.
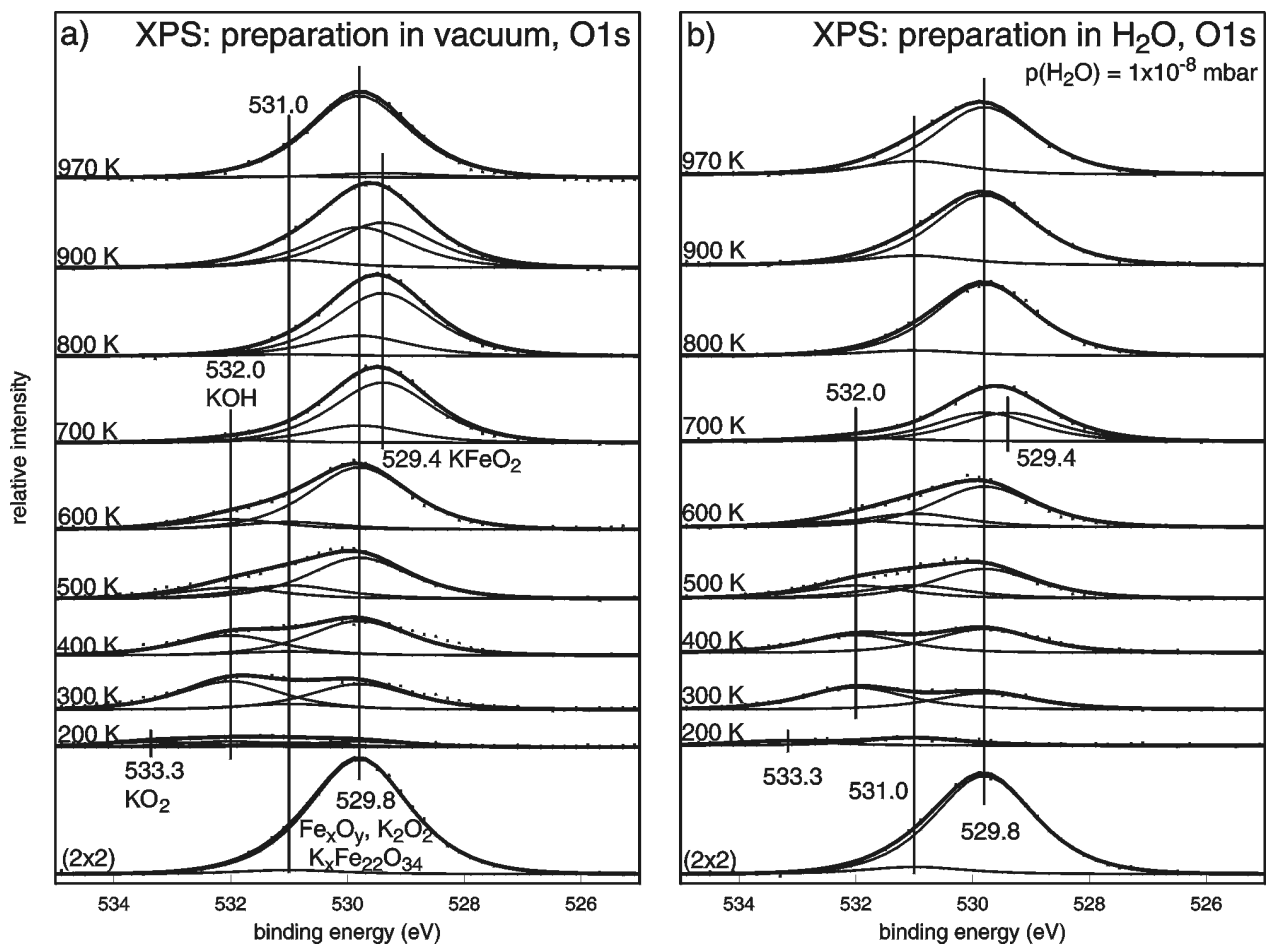

Fig. 8: $\mathrm{O} 1 \mathrm{~s} X P$ spectra $(\mathrm{h} v=1253.6 \mathrm{eV})$ of $\mathrm{KFe}_{\mathrm{x}} \mathrm{O}_{\mathrm{y}}-(2 \mathrm{x} 2)$, after deposition of a thick potassium layer at $200 \mathrm{~K}$ and after annealing to the indicated temperatures (a) in vacuum, (b) in $1 \times 10^{-8} \mathrm{mbar} \mathrm{H}_{2} \mathrm{O}$. The spectra were decomposed into Voigt curves. Their binding energies and assignment are indicated.

After potassium deposition at $200 \mathrm{~K}$ the Fe $2 p$ signal in fig.

7 is very small and structureless and the strong plasmon

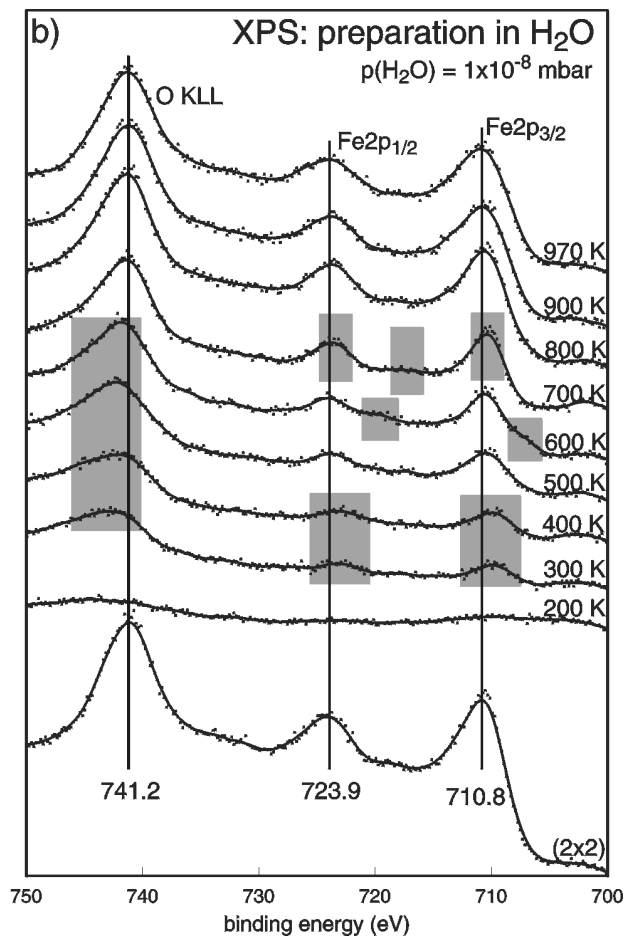

Figs. 7-9 present the XPS data for the $\mathrm{KFe}_{\mathrm{x}} \mathrm{O}_{\mathrm{y}}-(2 \mathrm{x} 2)$ phase (lowest spectra), after deposition of a thick metallic potassium layer on this surface at $200 \mathrm{~K}$ and after annealing this layer stepwise for $1 \mathrm{~min}$ at the indicated temperatures in vacuum (a) or 2 min in $10^{-8}$ mbar water (b). The total peak intensities of the peaks $\mathrm{Fe} 2 \mathrm{p}, \mathrm{O} 1 \mathrm{~s}, \mathrm{~K} 2 \mathrm{p}$ and in addition of the $\mathrm{K}_{\mathrm{KLL}}$ peak are included in fig. 13. 
the $\mathrm{K} 2 \mathrm{p}_{3 / 2}$ component is about $293.9 \mathrm{eV}$ which is lower than expected for the metal (294.4 eV [32] ). We cannot rule out that the surface is partly hydroxylated by residual gas water. This is confirmed by the small $\mathrm{O} 1 \mathrm{~s}$ signal in fig. 8 which shows components at $533.3,532.0$ and $529.8 \mathrm{eV}$. The signal at $532.0 \mathrm{eV}$ is characteristic for hydroxyl groups $[9,42,43]$ and we assign it to $\mathrm{KOH}$ formed by reaction with residual gas water according to

$$
2 \mathrm{~K}+\mathrm{H}_{2} \mathrm{O} \longrightarrow 2 \mathrm{KOH}+\mathrm{H}_{2} \uparrow .
$$

In agreement with literature[44] we interpret the $533.3 \mathrm{eV}$ component to $\mathrm{KO}_{2}$ which must have formed by reaction with oxygen of the substrate having diffused into the potassium layer as also expected from thermodynamics at this temperature (see fig. 2a):

$$
2 \mathrm{Fe}_{3} \mathrm{O}_{4}+\mathrm{K} \longrightarrow \mathrm{KO}_{2}+6 \mathrm{FeO} \text {. }
$$

The third component at $529.8 \mathrm{eV}$ could be due to $\mathrm{K}_{2} \mathrm{O}_{2}$. Its $\mathrm{BE}$ was observed between $529.7 \mathrm{eV}$ and $532.0 \mathrm{eV}[44-48] \mathrm{so}$ that a clear identification is difficult. The $\mathrm{BE}$ for oxygen in $\mathrm{Fe}_{3} \mathrm{O}_{4}$ is found at the same energetic position. Since the escape depth for the $\mathrm{O} 1 \mathrm{~s}$ emission is larger than for $\mathrm{Fe} 2 \mathrm{p}$ a contribution from the iron oxide cannot be ruled out either.

An anneal to only $300 \mathrm{~K}$ brings back appreciably intensities into the $\mathrm{Fe}$ and $\mathrm{O}$ derived signals and removes the plasmon losses in the $\mathrm{K} 2 \mathrm{p}$ emission indicating the removal of the K-multilayer in agreement with TDS (fig. 6a) which showed the onset of desorption at about $290 \mathrm{~K}$. Since desorption is of zero order, the multilayer is removed com-

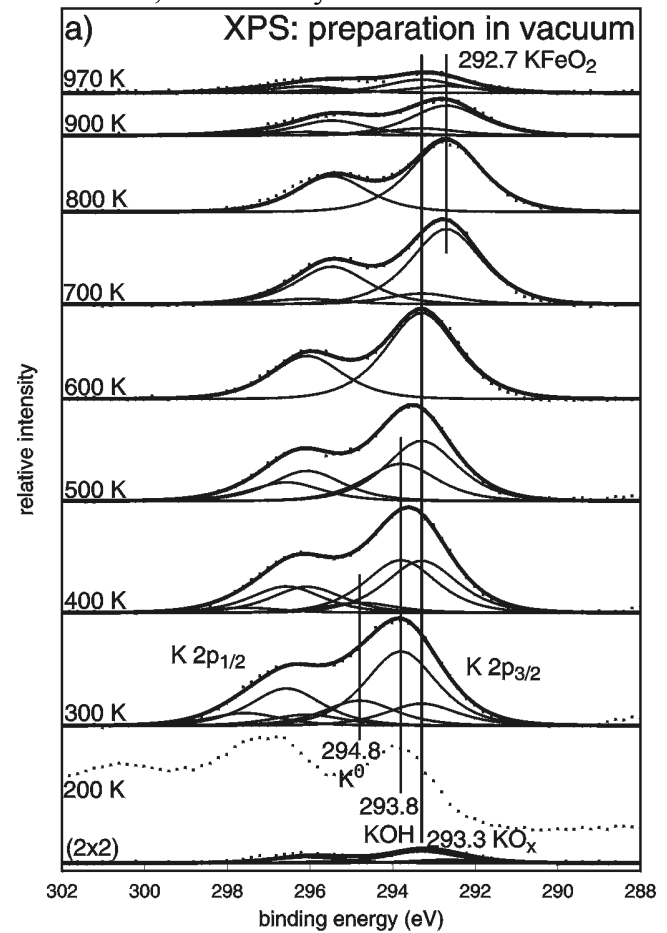

pletely after an anneal of $1 \mathrm{~min}$ at $300 \mathrm{~K}$. The XPS peak positions at 300 and $400 \mathrm{~K}$ are very similar to each other. Compared to the $\mathrm{KFe}_{\mathrm{x}} \mathrm{O}_{\mathrm{y}}-(2 \mathrm{x} 2)$ or $\mathrm{Fe}_{3} \mathrm{O}_{4}$ surface, the iron signals are shifted to lower binding energy consistent with a partial reduction of $\mathrm{Fe}^{3+}$ to $\mathrm{Fe}^{2+}$.

The existence of $\mathrm{KOH}$ is concluded from the intense $\mathrm{O} 1 \mathrm{~s}$ and $\mathrm{K} 2 \mathrm{p}$ components at 532.0 and $293.8 \mathrm{eV}$ [9][43] . Also some oxidic potassium $(529.8,293.3 \mathrm{eV})[49]$ and still some $\mathrm{K}^{0}$ at $294.8 \mathrm{eV}$ [49] can be identified. It is likely that the oxide is $\mathrm{K}_{2} \mathrm{O}_{2}$ since according to the thermodynamic calculations presented in fig. $2 \mathrm{a}, \mathrm{b}$ this is the most stable form in this temperature range. This $\mathrm{K}_{2} \mathrm{O}_{2}$ could be formed by

$$
2 \mathrm{Fe}_{3} \mathrm{O}_{4}+2 \mathrm{~K} \longrightarrow \mathrm{K}_{2} \mathrm{O}_{2}+6 \mathrm{FeO} \text {. }
$$

$\mathrm{KO}_{2}$ and $\mathrm{K}_{2} \mathrm{O}$ can be ruled out since their $\mathrm{O}$ 1s peak positions would be expected at 533.3 [44] and 528.0 [46-48] The spectra at $500 \mathrm{~K}$ show the same $\mathrm{O} 1 \mathrm{~s}$ and $\mathrm{K} 2 \mathrm{p}$ components with only slightly modified intensities. The Fe $2 p$ peak, however, is shifted back to the $\mathrm{Fe}_{3} \mathrm{O}_{4}$ position indicating a reoxidation of the iron oxide. The amount of $\mathrm{KOH}$ on the surface decreases with increasing temperature indicating potassium hydroxide decomposition and/or desorption as expected to occur at these temperatures[43] (compare fig. 2c). The intensity of the signal attributed to $\mathrm{K}^{0}$ also decreases. This could be due to a desorption of the potassium or a progress of the oxide or hydroxide formation.

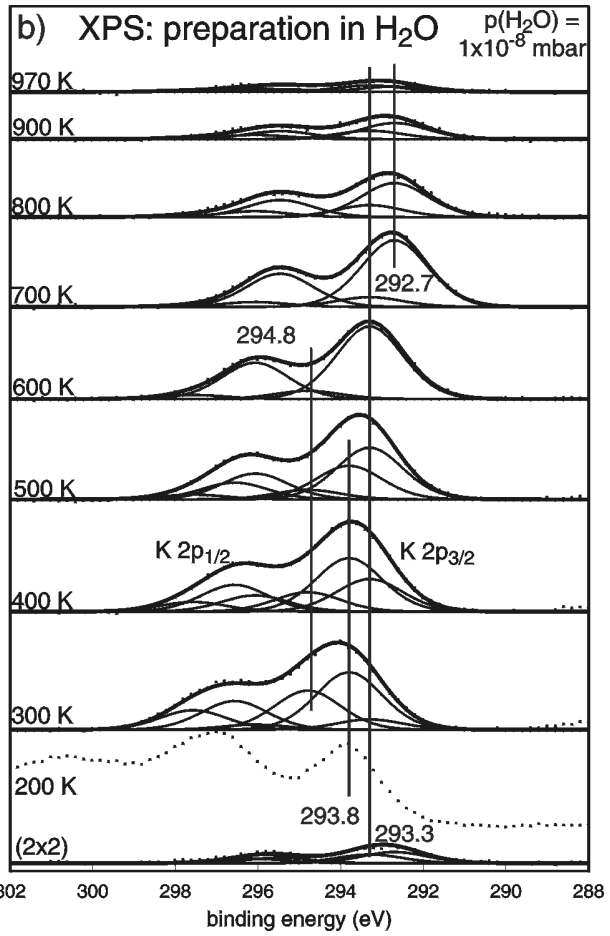

Fig. 9: $\mathrm{K} 2 \mathrm{p} \mathrm{XP}$ spectra $\left(\mathrm{h} v=1253.6 \mathrm{eV}\right.$ ) of $\mathrm{KFe}_{\mathrm{r}} \mathrm{O}_{\mathrm{y}}-(2 \times 2)$, after deposition of a thick potassium layer at $200 \mathrm{~K}$ (dotted) and after annealing to the indicated temperatures (a) in vacuum, (b) in $1 \times 10^{-8}$ mbar $\mathrm{H}_{2} \mathrm{O}$. The spectra were decomposed into Voigt curves. Their binding energies and assignment are indicated. The spin orbit split was fixed at $2.77 \mathrm{eV}$, the $\mathrm{K} 2 \mathrm{p}_{1 / 2} / \mathrm{K} 2 \mathrm{p}_{3 / 2}$ ratio at 0.5 .

At $600 \mathrm{~K}$ only components corresponding to oxidic potassium, iron oxide and in fig. $7 \mathrm{~b}$ also to $\mathrm{Fe}^{0}$ are visible. The reduction of the oxidic iron to $\mathrm{Fe}^{0}$ is consistent with the observation from TDS, where the sharp peak of $\mathrm{K}$ at $550 \mathrm{~K}$ was assigned to desorption from metallic $\mathrm{Fe}$. The $\mathrm{Fe}^{0}$ species exists obviously only within a narrow temperature range. That it is not visible upon annealing in vacuum (fig. $7 \mathrm{a}$ ) is most likely due to slightly different temperatures or the different annealing time for both preparations. Also the thermodynamic calculations agree. For potassium metal in contact with the magnetite surface and spatially isolated from the gas phase, equitherm calculations without admission of a gas phase indeed reveal that up to $704 \mathrm{~K}$ magnetite gets reduced by the potassium metal to form metallic iron and $\mathrm{K}_{2} \mathrm{O}$ :

$$
\begin{gathered}
\mathrm{Fe}_{3} \mathrm{O}_{4}+8 \mathrm{~K} \rightarrow 3 \mathrm{Fe}+4 \mathrm{~K}_{2} \mathrm{O}, \\
\Delta \mathrm{G}=-157.6 \mathrm{~kJ} / \mathrm{mol}, \quad(\mathrm{T}=600 \mathrm{~K}) .
\end{gathered}
$$

In fig. 10, the $\mathrm{Fe} 2 \mathrm{p}$ spectra of $\mathrm{Fe}_{3} \mathrm{O}_{4}, \mathrm{KFe}_{\mathrm{x}} \mathrm{O}_{\mathrm{y}}-(2 \mathrm{x} 2)$ and the $\mathrm{Fe}^{0}$ containing spectrum after annealing to $600 \mathrm{~K}$ in water atmosphere from fig. $7 \mathrm{~b}$ were tried to fit by a sum of the corresponding $\mathrm{Fe}^{0}, \mathrm{Fe}^{2+}$ and $\mathrm{Fe}^{3+}$ reference spectra from 
fig. 5. The spectra of $\mathrm{Fe}_{3} \mathrm{O}_{4}$ and $\mathrm{KFe}_{\mathrm{x}} \mathrm{O}_{\mathrm{y}}$ can easily be fitted with $\mathrm{Fe}^{2+}$ and $\mathrm{Fe}^{3+}$ components. The fit of the $600 \mathrm{~K}$ spectrum proves clearly the existence of $\mathrm{Fe}^{0}$. However, the measured main $\mathrm{Fe} 2 \mathrm{p}$ peak of $\mathrm{K}+\mathrm{Fe}_{3} \mathrm{O}_{4} / 600 \mathrm{~K}$ at $710 \mathrm{eV}$ is quite narrow and cannot be fitted reasonably using the reference spectra from fig. 4 . This holds also for the $700 \mathrm{~K}$ and $800 \mathrm{~K}$ spectra both in vacuum and in water atmosphere and indicates the existence of an additional iron containing phase.

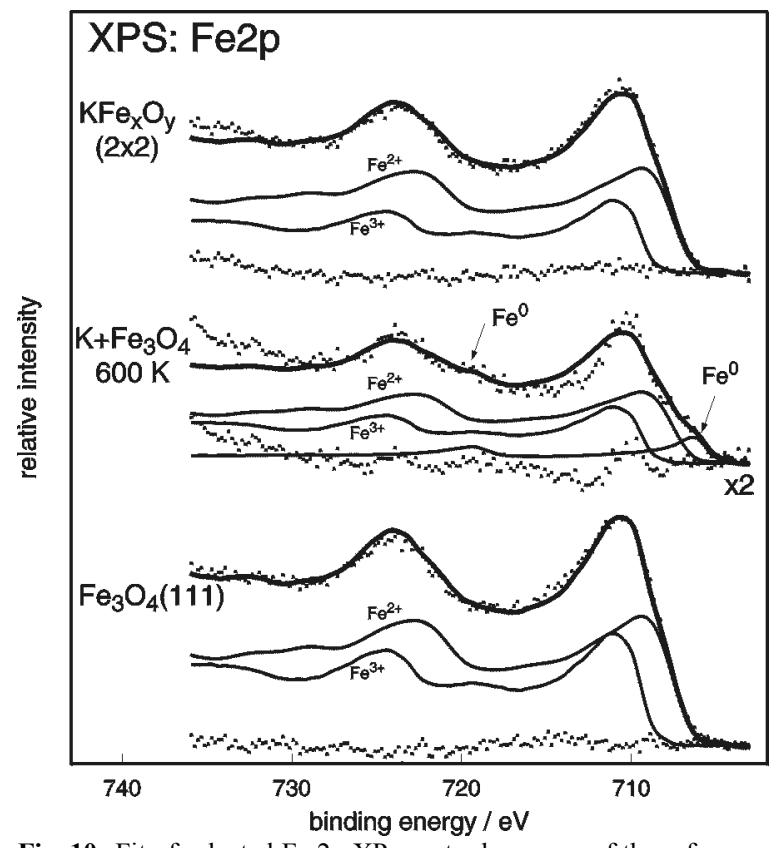

Fig. 10: Fit of selected Fe 2p XP spectra by a sum of the reference spectra for $\mathrm{Fe}, \mathrm{FeO}(111)$ and $\mathrm{Fe}_{2} \mathrm{O}_{3}(0001)$ representing $\mathrm{Fe}^{0}, \mathrm{Fe}^{2+}$ and $\mathrm{Fe}^{3+}$. The residues are also shown.

Also at $700 \mathrm{~K}$, both the $\mathrm{O} 1 \mathrm{~s}$ and the $\mathrm{K} 2 \mathrm{p}$ signals contain only one dominating component suggesting a homogeneous phase. This phase must be K-rich because the $\mathrm{K}$ signals are quite intense. The signals of all elements in this range in figs. 7-9 are shifted towards smaller BE, also that of $\mathrm{Fe} 2 p$, which has been observed earlier for $\mathrm{KFeO}_{2}$ [50]. Since the typical $\mathrm{Fe}^{3+}$-derived satellites have gained intensity, this shift is obviously not due to a reduction, but to the formation of a ternary phase with a coordination of Fe both to oxygen and potassium. The considerations in section 2.1 also suggest the formation of $\mathrm{KFeO}_{2}$ at these low temperatures while at higher temperatures the $\mathrm{K}_{\mathrm{x}} \mathrm{Fe}_{22} \mathrm{O}_{34}(\mathrm{x}=2,4)$ phases may be formed which contain $\mathrm{Fe}^{3+}$ as well. Qualitatively, not much has changed at $800 \mathrm{~K}$. Only the relative and absolute intensities have changed slightly.

Beyond $800 \mathrm{~K}$, the potassium content decreases rapidly, the $\mathrm{O} 1 \mathrm{~s}$ and the $\mathrm{Fe} 2 \mathrm{p}$ signals shift back, the Fe $2 \mathrm{p}$ spectra loose the $\mathrm{Fe}^{3+}$ satellite feature resulting in a spectrum similar to the $\mathrm{KFe}_{\mathrm{x}} \mathrm{O}_{\mathrm{y}}-(2 \mathrm{x} 2)$ phase. However, the $(2 \times 2)$ LEED pattern can be restored only after an extended annealing at $970 \mathrm{~K}$ in vacuum or in $10^{-6} \mathrm{mbar}$ oxygen.

Generally, the spectra after annealing in water atmosphere show the same behaviour and the same components as after annealing in vacuum. The most significant difference, however, is that the depletion of the potassium is clearly faster and starts already beyond $700 \mathrm{~K}$. This is related with a rapid decrease of the features attributed to $\mathrm{KFeO}_{2}$, i.e. shift of the Fe $2 p$ peak back to the position in $\mathrm{KFe}_{\mathrm{x}} \mathrm{O}_{\mathrm{y}}$ (2x2), disappearance of the $529.4 \mathrm{eV}$ component of $\mathrm{O} 1 \mathrm{~s}$ and decrease of the $292.7 \mathrm{eV}$ component of $\mathrm{K} \mathrm{2p}$. This is not due to the longer annealing time $(2 \mathrm{~min}$ vs. $1 \mathrm{~min}$ in vacuum) since even prolonged heating in vacuum at $970 \mathrm{~K}$ does not result in a potassium depletion as large as after 2 min in water atmosphere. We attribute this accelerated loss of potassium to the fomation of $\mathrm{KOH}$ and its instantanious decomposition and/or desorption.

In summary all observed peak positions with their assignment are listed in table 2 .

\begin{tabular}{|c|c|c|c|c|c|}
\hline Compound & $\mathrm{Fe} 2 \mathrm{p}_{3 / 2}$ & $\mathrm{Fe} 2 \mathrm{p}_{1 / 2}$ & Fe 2p-sat. & $\mathrm{O} 1 \mathrm{~s}$ & $\mathrm{~K} 2 \mathrm{p}_{3 / 2}$ \\
\hline $\mathrm{Fe}^{0}$ & 707.0 & 720.1 & - & - & - \\
\hline $\mathrm{FeO}(111)$ & 709.6 & 722.7 & 715.5 & 529.8 & - \\
\hline $\mathrm{Fe}_{3} \mathrm{O}_{4}(111)$ & 710.8 & 723.9 & $715.5,719.3$ & 529.8 & - \\
\hline $\mathrm{Fe}_{2} \mathrm{O}_{3}(0001)$ & 711.1 & 724.2 & 719.3 & $\begin{array}{l}529.8 \\
\end{array}$ & - \\
\hline $\mathbf{K}^{0}$ & - & - & - & - & 294.8 \\
\hline KOH & - & - & - & 532.0 & 293.8 \\
\hline $\mathrm{KO}_{2}$ & - & - & - & 533.3 & 293.2 \\
\hline $\mathbf{K}_{2} \mathbf{O}_{2}$ & - & - & - & 529.8 & 293.3 \\
\hline $\mathrm{KFeO}_{2}$ & 710.2 & 723.2 & 718.5 & 529.4 & 292.7 \\
\hline$K_{x} F_{22} O_{34}$ & 710.8 & 723.9 & $715.5,719.3$ & 529.8 & 293.0 \\
\hline
\end{tabular}

Table 2: XPS Peakpositions of all identified compounds in $\mathrm{eV}$

\subsection{Stoichiometry of $\mathrm{K}-\mathrm{Fe}-\mathrm{O}$ phases}

Fig. 11 presents the ratios $\mathrm{J}(\mathrm{K} 2 \mathrm{p}) / \mathrm{J}\left(\mathrm{K}_{\mathrm{LMM}}\right)$ of the corresponding peak areas in the XP spectra. They span a range from about $0.22-0.25$ for the $\mathrm{KFe}_{\mathrm{x}} \mathrm{O}_{\mathrm{y}}-(2 \mathrm{x} 2)$ film to 0.46 for the thick potassium layer on $\mathrm{Fe}_{3} \mathrm{O}_{4}$ annealed in vacuum to $300-400 \mathrm{~K}$. The value for homogeneous distribution of potassium as in the thick metallic film is about 0.38 . At $300-500 \mathrm{~K}$ the surface is slightly $\mathrm{K}$-depleted, probably because of formation of surface $\mathrm{KOH}$ by reaction with water from the residual gas as deduced from the XPS peak shape analysis. A fairly homogenious potassium distribution is observed at $600-700 \mathrm{~K}$. Beyond this temperature a relative enrichment of the potassium at the surface (or depletion in the bulk) is observed. In order to identify the different observed $\mathrm{K}-\mathrm{Fe}-\mathrm{O}$ phases, the measured integrated intensities of the four XPS peaks $\mathrm{K} 2 \mathrm{p}, \mathrm{K}_{\mathrm{LMM}}, \mathrm{Fe} 2 \mathrm{p}$ and $\mathrm{O}$ $1 \mathrm{~s}$ were analysed using the discrete layer model described in section 3.2.

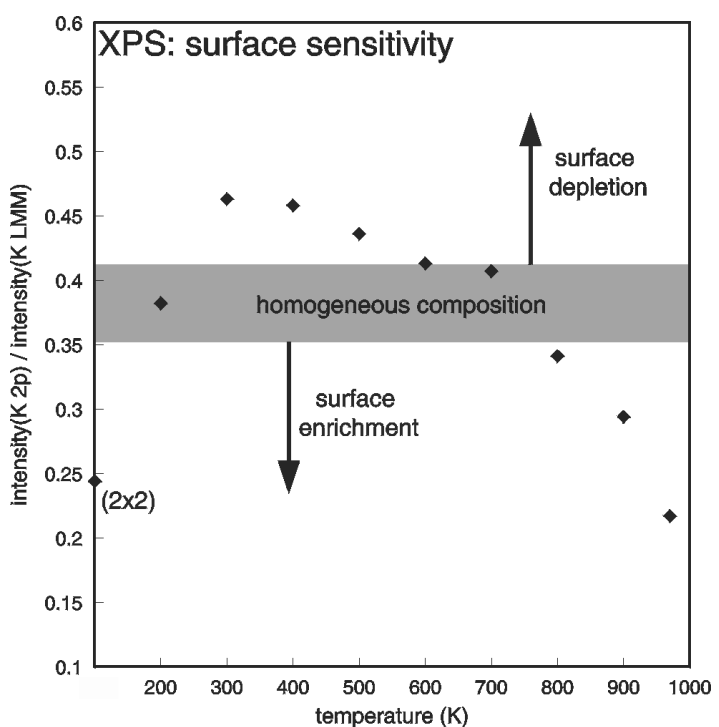

Fig. 11: Intensity ratio of the XPS peaks $K 2 p$ and $K_{L M M}$ for the $\mathrm{KFe}_{\mathrm{x}} \mathrm{O}_{\mathrm{y}}-(2 \mathrm{x} 2)$ phase, after deposition of a thick potassium layer at $200 \mathrm{~K}$ and after annealing to the indicated temperatures in vacuum. 
The $\mathrm{KFe}_{\mathrm{x}} \mathrm{O}_{\mathrm{y}}-(2 \mathrm{x} 2)$ LEED pattern was observed within a certain range of preparation conditions and XPS peak intensities. Fig. 12 shows the intensities of all surfaces with the $(2 \times 2)$ structure prepared on two $\mathrm{Fe}_{3} \mathrm{O}_{4}$ substrate films (cycles 1-3 and 4-6, respectively). As mentioned above, the (2x2) surface phase formed only after deposition of a minimum amount of potassium. This amount was $3-4 \times 10^{15} \mathrm{~cm}^{-2}$ corresponding to 6-8 metallic potassium layers as estimated applying the discrete layer model after K-deposition at 200 $\mathrm{K}$ before annealing. As demonstrated by the TDS measurements in section 4.2, most of this $\mathrm{K}$-amount must have been incorporated into the oxide bulk during annealing.

Cycle 1 in fig. 12 was measured after K-deposition and an anneal at $970 \mathrm{~K}$. Further annealing improved the quality of the $(2 \times 2)$ pattern which is best in cycle 2 . Cycle 3 was taken after annealing an additionally deposited thick metallic K-layer. In order to obtain a $(2 \times 2)$ pattern, prolonged annealing in vacuum or in $10^{-6}$ mbar $\mathrm{O}_{2}$ was necessary to remove the obviously too high K-content. Nevertheless, the pattern never got as sharp and intense as in cycle 2. Cycles 4-6 were measured on a freshly prepared $\mathrm{Fe}_{3} \mathrm{O}_{4}$ film and correspond to cycles $1-3$. Cycle 5 displayed the best $(2 \times 2)$ pattern. Its XPS intensities are very similar to those of cycle 2 . The low value of $J(K 2 p) / J\left(K_{L M M}\right)=0.22$ indicate $K$ enrichment at the surface. Since the absolute intensities of the $\mathrm{K} 2 \mathrm{p}$ and the $\mathrm{K}_{\mathrm{LMM}}$ peaks of the well ordered surfaces are low, the bulk must have a low K-content.

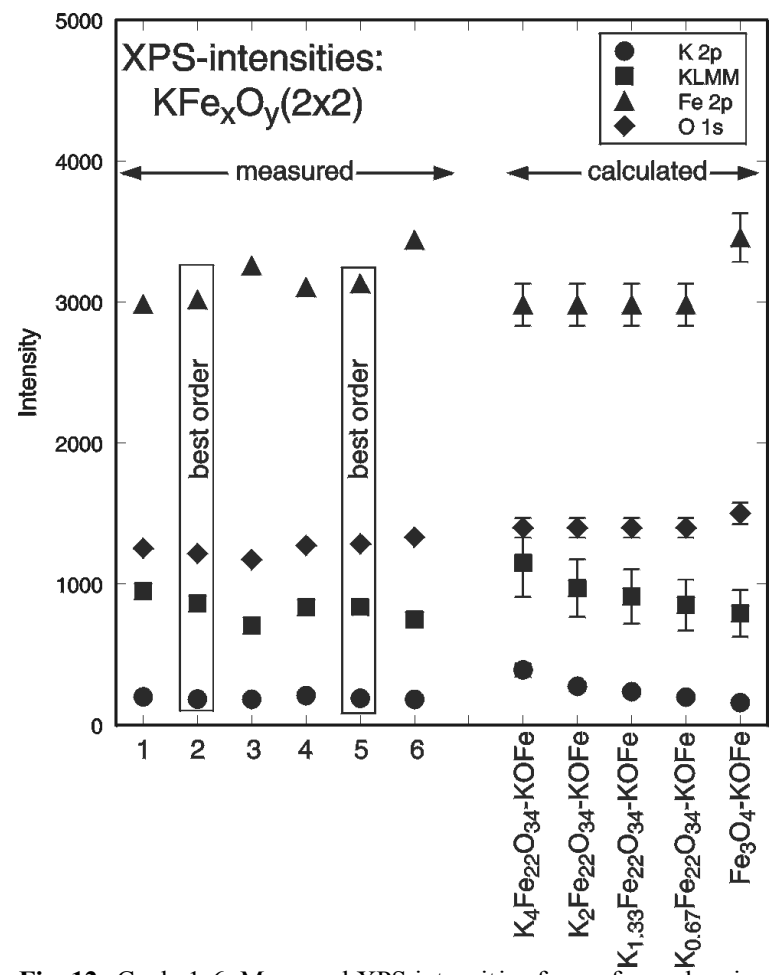

Fig. 12: Cycle 1-6: Measured XPS intensities for surfaces showing the $\mathrm{KFe}_{\mathrm{x}} \mathrm{O}_{\mathrm{y}}-(2 \times 2)$ phase prepared on two oxide films illustrating the composition range and reproducibility of preparation. The best ordered $(2 \times 2)$ surfaces were observed for cycles 2 and 5 . Right: calculated intensities for the model structures indicated below.

Bulk phases with low $\mathrm{K}$-content may be derived from the layered structure of $\mathrm{K}_{2} \mathrm{Fe}_{22} \mathrm{O}_{34}\left(\mathrm{~K}-\beta-\mathrm{Fe}_{2} \mathrm{O}_{3}\right)$ in fig. 3a. This structure can be considered as a sequence of spinel-like blocks $-\mathrm{O}_{4}-\mathrm{Fe}_{3}-\mathrm{O}_{4}$ - etc. like in $\mathrm{Fe}_{3} \mathrm{O}_{4}$ separated by $-\mathrm{Fe}$ $\mathrm{K}_{\mathrm{x}} \mathrm{O}$-Fe-layers $(0.67<\mathrm{x}<2)$. The similarity of the spinel blocks to $\mathrm{Fe}_{3} \mathrm{O}_{4}$ would explain the similarity of their $\mathrm{Fe} 2 \mathrm{p}$ spectra in fig. 5. Lower K-contents can be achieved either by increasing the thickness of the spinel blocks or by a decrease of the occupation of the potassium sublayers in analogy to the structure of corresponding alum clay miner- als. The right part of fig. 12 gives the intensities calculated for such model structures $\mathrm{K}_{\mathrm{x}} \mathrm{Fe}_{22} \mathrm{O}_{34}(\mathrm{x}=4,2,1.33$ and 0.67 ) as well as for $\mathrm{Fe}_{3} \mathrm{O}_{4}$, all terminated by a K-O-Fe surface layer as in fig. 3a. The uncertainty of the escape depths and the atomic volumes of $\mathrm{K}, \mathrm{Fe}$ and $\mathrm{O}$ in the adlayer cause an uncertainty of the calculated intensities. The error bars in fig. 12 represent the variations induced by variation of the escape depth ( $B$ in equ. (1) between 0.54 and 0.96 ). The agreement with the intensities of the well-ordered surface (cycles 2 and 5) is best for a bulk structure containing a low concentration of potassium $\left(\mathrm{K}_{0.67} \mathrm{Fe}_{22} \mathrm{O}_{34}\right)$. Considering the error limits, however, also the other tested bulk compositions cannot be ruled out. The essential contribution to the $\mathrm{K} 2 \mathrm{p}$ and $\mathrm{K}_{\mathrm{LMM}}$ XPS-intensities comes from the K-O-Fe surface layer. Its $\mathrm{K}$-concentration corresponds to only $3.3 \times 10^{14} \mathrm{~cm}^{-2}$.

The atomic distances in the (0001) plane of $\mathrm{K}_{2} \mathrm{Fe}_{22} \mathrm{O}_{34}$ are determined by the spinel blocks and are therefore almost identical to those on $\mathrm{Fe}_{3} \mathrm{O}_{4}(111)$. This is the reason why the observed LEED pattern looks exactly like a $(2 \times 2)$ pattern with respect to the original $\mathrm{Fe}_{3} \mathrm{O}_{4}(111)$ surface. The K-OFe-termination deduced from the quantitative analysis presented here which corresponds to the surface termination of $\mathrm{K}_{2} \mathrm{Fe}_{22} \mathrm{O}_{34}(0001)$ plotted in fig. 3a corresponds to a $(1 \mathrm{x} 1)$ periodicity with respect to $\mathrm{Fe}_{3} \mathrm{O}_{4}(111)$. We suggest that the actually observed (2x2) periodicity may be caused by an inplane relaxation/reconstruction of the K-O-Fe surface layer. It is pointed out that the close structural match between $\mathrm{Fe}_{3} \mathrm{O}_{4}$ and $\mathrm{K}_{2} \mathrm{Fe}_{22} \mathrm{O}_{34}$ was already found by electron diffraction in technical iron oxide catalysts for dehydrogenation of ethylbenzene to styrene[9]. This relation allowed the notion that $\mathrm{K}_{2} \mathrm{Fe}_{22} \mathrm{O}_{34}$ is a storage phase for $\mathrm{Fe}^{3+}$ and $\mathrm{K}^{+}$ions.

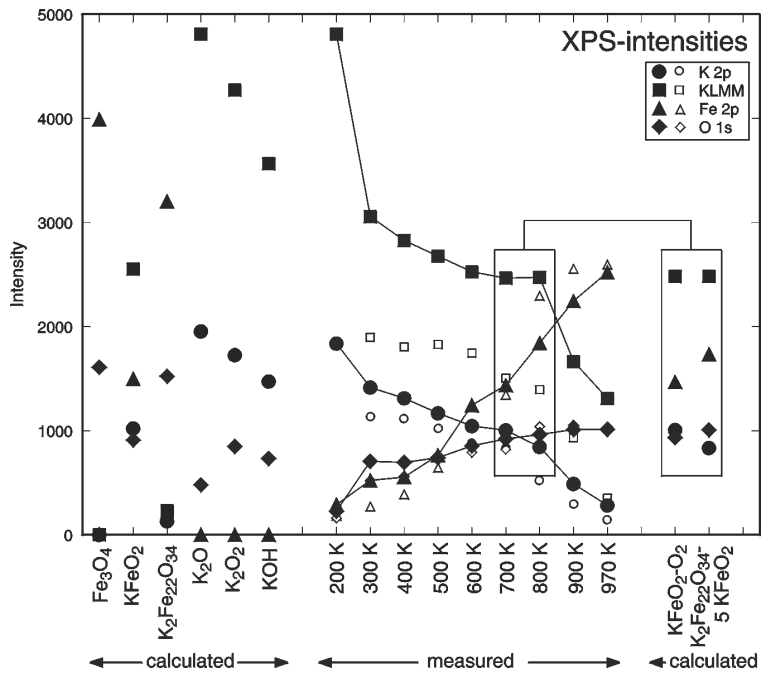

Fig. 13: Left: Calculated XPS intensities for the compounds indicated below; center: Measured intensities for a thick metallic potassium layer deposited at $200 \mathrm{~K}$ and after annealing to the indicated temperatures in vacuum (full symbols) and in $10^{-8} \mathrm{mbar}$ water (open symbols); right: calculated intensities for the model structures indicated below which fit best with the intensities measured at 700 and $800 \mathrm{~K}$.

Fig. 13 presents calculated intensities for a number of bulk materials and the measured intensities after deposition of a thick metallic K-layer at $200 \mathrm{~K}$ and annealing for $1 \mathrm{~min}$ at the indicated temperatures in vacuum (full symbols). After deposition, only the $\mathrm{K} 2 \mathrm{p}$ and the $\mathrm{K}_{\mathrm{LMM}}$ intensities are high. As discussed in the preceeding section, the small oxygen intensitiy is due to formation of $\mathrm{KOH}$ by interaction with the residual gas and to K-oxides by diffusion of oxygen from the substrate into the K-layer. Also a small Fe intensity is visible which may be a hint for beginning diffusion 
also of $\mathrm{Fe}$ into the film, even at this low temperature. At $300 \mathrm{~K}$ the $\mathrm{K}$ multilayer is desorbed in agreement with the TDS measurement and the oxygen and Fe intensity has substantially increased. Especially the $\mathrm{O}$ intensity has already increased to about $70 \%$ of the intensity which it reaches after annealing to $970 \mathrm{~K}$. With exception of the Fecontent, the intensity pattern resembles best that of $\mathrm{KOH}$ and $\mathrm{K}_{2} \mathrm{O}_{2}$, in complete agreement with the curve fitting analysis of the $\mathrm{O} 1 \mathrm{~s}$ and $\mathrm{K} 2 \mathrm{p}$ peaks presented in figs. 8a and $9 \mathrm{a}$ and in agreement with thermodynamics (fig. 2a-c). The desorption of the chemisorbed species observed by TDS beween 380 and $550 \mathrm{~K}$ is associated with a further decrease of the $\mathrm{K}$ emission and an increase of the $\mathrm{Fe}$ and $\mathrm{O}$ peaks in this range. Starting at $500 \mathrm{~K}$, the Fe $2 p$ intensity increases continuously and much more steeply than the $\mathrm{O}$ 1s intensity. This indicates that $\mathrm{Fe}$ penetrates into the surface film. This is accompanied by a slow decrease of the Kcontent. At $700 \mathrm{~K}$, the $\mathrm{J}(\mathrm{K} 2 \mathrm{p}) / \mathrm{J}\left(\mathrm{K}_{\mathrm{LMM}}\right)$ ratio in fig. 11 indicated a homogeneous $\mathrm{K}$-distribution. The $\mathrm{K}$ intensity still is roughly half that of the thick potassium layer at 200 $\mathrm{K}$ corresponding to a potassium rich bulk phase. At 700 and $800 \mathrm{~K}$, XPS had revealed characteristic phases with the maxima of $\mathrm{Fe} 2 \mathrm{p}, \mathrm{O} 1 \mathrm{~s}$ and $\mathrm{K} 2 \mathrm{p}$ shifted towards smaller $\mathrm{BE}$. The $\mathrm{O} 1 \mathrm{~s}$ and $\mathrm{K} 2 \mathrm{p}$ emission contained one dominant component and ternary phases were suggested. This is strongly supported by comparison of the measured intensities in fig. 13 with the calculated ones on the right in fig. 13. The $700 \mathrm{~K}$ phase fits very well with $\mathrm{KFeO}_{2}$. For the calculation, an orientation and complete oxygen termination as in fig. $3 \mathrm{~b}$ was assumed. But since the elemental distribution in $\mathrm{KFeO}_{2}$ is fairly homogeneous, the surface orientation has no significant influence on the calculated results. The $800 \mathrm{~K}$ phase contains more $\mathrm{Fe}$ and less $\mathrm{K}$ in the bulk as reflected by the decrease of the $\mathrm{K} 2 \mathrm{p}$ emission whereas the constant $\mathrm{K}_{\mathrm{LMM}}$ intensity indicates a constant $\mathrm{K}$ content in the near-surface region. An excellent fit is possible assuming a layer consisting of 5 formula units of $\mathrm{KFeO}_{2}$ (the marked $1 / 4$ bulk repeat unit in fig. 3b corresponds to 4 formula units) on top of a bulk consisting of $\mathrm{K}_{2} \mathrm{Fe}_{22} \mathrm{O}_{34}$. Since this is a layered structure, the fitted thickness of the $\mathrm{KFeO}_{2}$ layer depends on the used escape depth values and would increase to 7 formula units for $B=0.96$ instead of 0.54 in equ. (1). At $900-970 \mathrm{~K}$ the $\mathrm{K}$-content decreases strongly and approaches the composition of the $\mathrm{KFe}_{\mathrm{x}} \mathrm{O}_{\mathrm{y}}-(2 \mathrm{x} 2)$ phase $\left(\mathrm{K}_{0.67} \mathrm{Fe}_{22} \mathrm{O}_{34}\right)$. However, as mentioned, prolonged annealing at $970 \mathrm{~K}$ in vacuum or $\mathrm{O}_{2}$ is necessary to restore the composition and surface periodicity of this phase completely.

As mentioned in section 2.1, Dvoretskii et al.[23] found that the formation of $\mathrm{KFeO}_{2}$ dominates at low temperatures while potassium polyferrites $\left(\mathrm{K}_{2} \mathrm{Fe}_{22} \mathrm{O}_{34}+\mathrm{K}_{4} \mathrm{Fe}_{22} \mathrm{O}_{34}\right)$ are formed beyond about $1000 \mathrm{~K}$. We observed polyferrite formation at 900-970 K. The difference in the temperature of the phase transition is probably due to the different ambient gas pressures. In fact, at reduced pressure (1 mbar) Dvoretskii et al. observed the phase transition already at 870 $\mathrm{K}[28]$.

When annealing in $\mathrm{H}_{2} \mathrm{O}$ atmosphere (open symbols in fig. 13), the surface sensitive $\mathrm{K}_{\mathrm{LMM}}$ intensity is considerally lower and the more bulk sensitive $\mathrm{K} 2 \mathrm{p}$ intensity is slightly lower in the whole range. This might be due to complete hydroxilation of the near-surface potassium and, starting at $400-500 \mathrm{~K}$, to surface depletion by $\mathrm{KOH}$ desorption as supported by our thermodynamic calculations (fig. 2c). In addition, the strong drop of the potassium intensity observed at $900-970 \mathrm{~K}$ when annealing in vacuum, starts already at $700-800 \mathrm{~K}$ and results in strong $\mathrm{K}$ depletion at 970 $\mathrm{K}$. It is obvious that water is essential for the reduction of the potassium content by $\mathrm{KOH}$ formation and desorption in this high-temperature range. Most likely even when annealing in vacuum, residual gas water is essential for $\mathrm{K}$ removal.

\section{Conclusions}

We have presented an analysis of the formation and composition of potassium promoted iron oxide films combining a binding energy and intensity analysis of XPS peaks with TDS and thermodynamic considerations.

The well ordered $\mathrm{KFe}_{\mathrm{x}} \mathrm{O}_{\mathrm{y}}-(2 \mathrm{x} 2)$ phase surface is formed by deposition of potassium on the $\mathrm{Fe}_{3} \mathrm{O}_{4}(111)$ substrate and annealing at $970 \mathrm{~K}$. The necessary potassium amount was $3-4 \times 10^{15} \mathrm{~cm}^{-2}$ for our oxide films of roughly $100 \AA$ thickness. There is strong evidence that an appreciable portion of this potassium is incorporated into the substrate during annealing. The result, however, is a substrate which still is essentially $\mathrm{Fe}_{3} \mathrm{O}_{4}$-like as evidenced by the peak positions and shapes of the $\mathrm{Fe} 2 \mathrm{p}$ and $\mathrm{O} 1 \mathrm{~s}$ peaks. Our analysis suggests that it is of the $\mathrm{K}_{\mathrm{x}} \mathrm{Fe}_{22} \mathrm{O}_{34}$-type with $0<\mathrm{x}<2$. The surface contains about one $\mathrm{K}$ atom per $\mathrm{Fe}_{3} \mathrm{O}_{4}(111)$ unit cell or four $\mathrm{K}$ atoms per $\mathrm{KFe}_{\mathrm{x}} \mathrm{O}_{\mathrm{y}}-(2 \times 2)$ unit cell. The main contribution to the potassium XPS intensity comes from this surface layer. A detailed structural model does not yet exist.

Fig. 14 summarizes schematically the phases and compositions deduced from the binding energy and intensity analysis of XPS peaks. The starting point is either the clean $\mathrm{Fe}_{3} \mathrm{O}_{4}$ surface or the $\mathrm{KFe}_{\mathrm{x}} \mathrm{O}_{\mathrm{y}}-(2 \times 2)$ phase onto which a thick metallic potassium layer is deposited at $200 \mathrm{~K}$. Due to the high reactivity of this layer, it is covered by some $\mathrm{KOH}$ due to reaction with residual gas water and contains $\mathrm{KO}_{2}$ due to reaction with oxygen from the substrate. These phases agree with the thermodynamically predicted ones.

At 300 and $400 \mathrm{~K}$, the $\mathrm{Fe} 2 \mathrm{p}$ peak shift indicates partial reduction of $\mathrm{Fe}_{3} \mathrm{O}_{4}$ to $\mathrm{FeO}$, the metallic $\mathrm{K}^{0}$-content is strongly reduced and $\mathrm{K}$-oxide formation in the form of $\mathrm{K}_{2} \mathrm{O}_{2}$ has proceeded as expected from thermodynamics. The KOH-content has also increased. At $500 \mathrm{~K}, \mathrm{KOH}$ starts to decompose and/or to desorb. There is evidence from TDS and also from XPS that some iron is reduced to $\mathrm{Fe}^{0}$ around $550-600 \mathrm{~K}$. The $\mathrm{Fe}^{0}$ has disappeared from the XPS analysis depth at or beyond $600 \mathrm{~K}$. Since desorption is unlikely, we suggest that it may have formed metallic aggregates which have diffused to the Pt-oxide interface or is reoxidized.

Although the $\mathrm{K} 2 \mathrm{p}$ peak is narrow at $600 \mathrm{~K}$ which would be consistent with the existence of only one phase, the intensities cannot be fitted assuming a known homogeneous K-Fe$\mathrm{O}$ bulk phase. The $\mathrm{O} 1 \mathrm{~s}$ peak still contains a $\mathrm{OH}$ contribution. Therefore we believe that the layer still mainly consists of potassium oxides and hydroxides, possible with nuclei of $\mathrm{KFeO}_{2}$.

At $700 \mathrm{~K}$, the whole layer has transformed to $\mathrm{KFeO}_{2}$. This is supported by a characteristic shift of all XPS peaks to lower BE and by their sharpness suggesting one homogeneous phase. The Fe $2 p$ emission is unusually sharp and cannot be fitted simply by a sum of $\mathrm{Fe}^{2+}$ (as in $\mathrm{FeO}$ ) and $\mathrm{Fe}^{3+}$ (as in $\mathrm{Fe}_{2} \mathrm{O}_{3}$ ) contributions. It is shifted towards lower $\mathrm{BE}$ although the existence of the characteristic $\mathrm{Fe}^{3+}$ satellite suggests that $\mathrm{Fe}$ is not reduced. This is compatible with a ternary compound with $\mathrm{Fe}$ coordinated to both $\mathrm{K}$ and $\mathrm{O}$. The intensity ratio of the $\mathrm{K} 2 \mathrm{p}$ to $\mathrm{K}_{\mathrm{LMM}}$ peaks shows that potassium is homogeneously distributed. The quantitative analysis agrees perfectly with the stoichiometry of $\mathrm{KFeO}_{2}$ and also thermodynamics suggest the formation of $\mathrm{KFeO}_{2}$ at these temperatures at low pressures. 


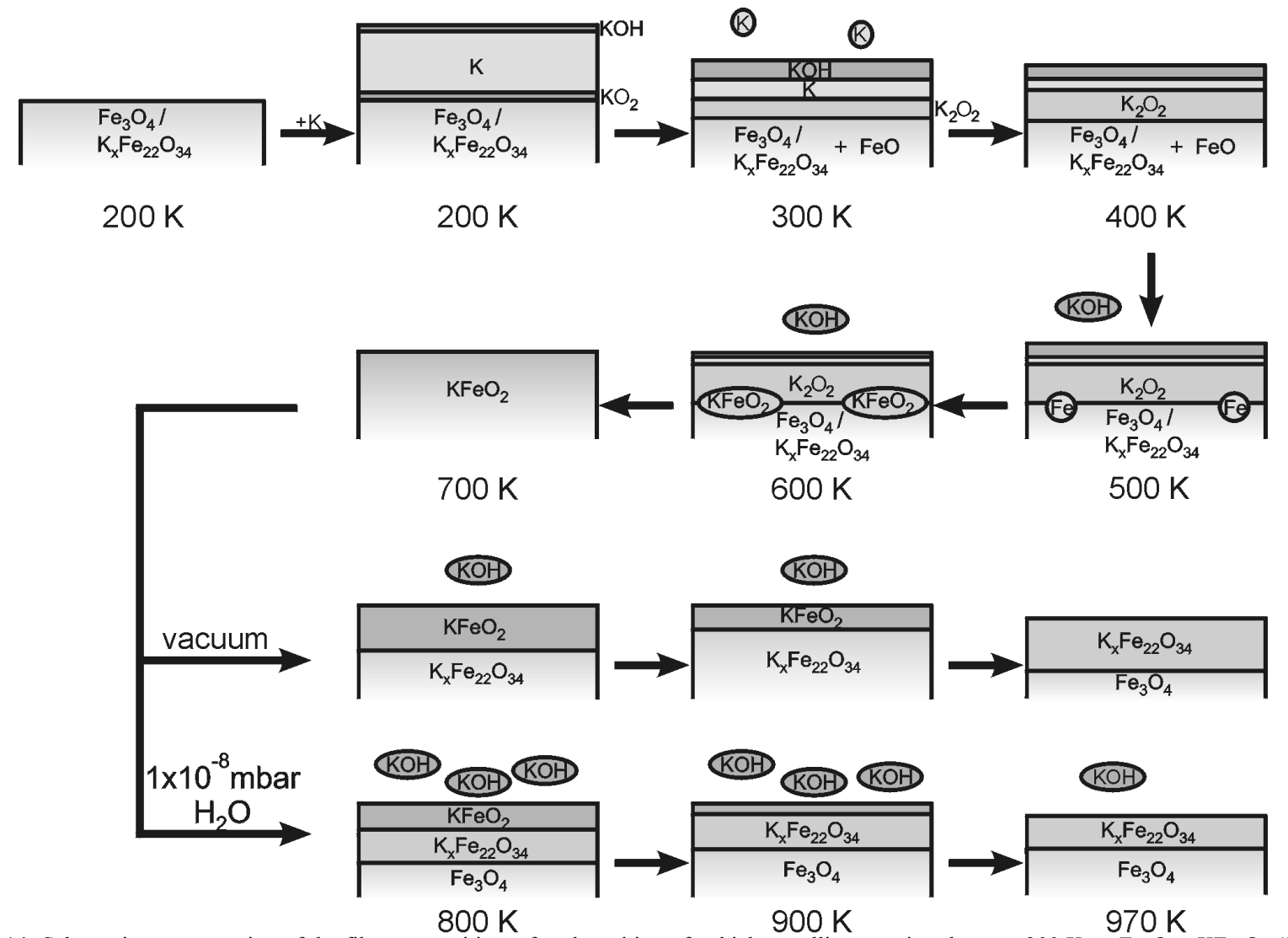

Fig. 14: Schematic representation of the film composition, after deposition of a thick metallic potassium layer at $200 \mathrm{~K}$ on $\mathrm{Fe}_{3} \mathrm{O}_{4}$ or $\mathrm{KFe}_{\mathrm{x}} \mathrm{O}_{\mathrm{y}}-(2 \times 2)$ and after annealing to the indicated temperatures in vacuum or in $10^{-8} \mathrm{mbar}$ water.

At $800 \mathrm{~K}$ and beyond, the potassium content of the film decreases further. Surprisingly, this starts from the bulk by formation of $\mathrm{K}_{\mathrm{x}} \mathrm{Fe}_{22} \mathrm{O}_{34}(\mathrm{x} \approx 2)$ with the near surface layer remaining the $\mathrm{K}$-rich $\mathrm{KFeO}_{2}$-phase. With increasing temperature, the interface between these phases moves towards the surface. At $970 \mathrm{~K}$ the $\mathrm{KFeO}_{2}$ layer has disappeared and a thin $\mathrm{K}_{\mathrm{x}} \mathrm{Fe}_{22} \mathrm{O}_{34}(\mathrm{x}=0.67-2)$ layer on top of $\mathrm{Fe}_{3} \mathrm{O}_{4}$ is the most likely arrangement. The removal of $\mathrm{K}$ is faster in water atmosphere, probably due to formation and decomposition or evaporation of $\mathrm{KOH}$. We suggest that even under vacuum the water partial pressure in the residual gas is mainly responsible for the potassium removal. Finally, prolonged heating at $970 \mathrm{~K}$ under vacuum or oxygen atmosphere restores the $\mathrm{KFe}_{\mathrm{x}} \mathrm{O}_{\mathrm{y}}-(2 \times 2)$ surface.

Potassium promoted iron oxide catalysts are used in the dehydrogenation of ethylbenzene to styrene. Muhler et al. [8] have presented evidence that $\mathrm{KFeO}_{2}$ is the catalytically active phase whereas the catalyst bulk consists of $\mathrm{K}_{2} \mathrm{Fe}_{22} \mathrm{O}_{34}$ which serves as potassium reservoir. Our study has shown that such a layer structure with the K-rich $\mathrm{KFeO}_{2}$ phase on top also forms on the well-defined model catalyst films investigated here at the usual temperatures of application of the technical catalyst $(870 \mathrm{~K})$. This supports strongly the interpretation of Muhler et al. [8]. Treatment with water even at only $10^{-8}$ leeds to potassium depletion of the near surface region of the model catalyst. The technical catalyst is operated under excess of water (partial pressure around 900 mbar) which should result in a fast K-depletion and deactivation. In fact, deactivation by formation of seperated phases of $\mathrm{Fe}_{3} \mathrm{O}_{4}$ and $\mathrm{KOH}$ is finally observed. However, this is a slow process. Therfore it is likely that the complete coverage of the active K-promoted catalyst by carbonaceous deposites [51] also serves as a protective layer against K-depletion.

\section{Acknowledgement}

This project was funded in part by the Deutsche Forschungsgemeinschaft (Contract No. WE 1372/5-2). The authors thank M. Swoboda for technical support and Sh. Shaikhutdinov for helpful discussions.

\section{References}

[1] H. P. Bonzel, A. M. Bradshaw, and G. Ertl (Ed.); Physics and Chemistry of Alkali Metal Adsorption, Materials Science Monographs, 57; Elsevier, (1989)

[2] W.D. Mross; Catal. Rev. Sci. Eng. 25, 591 (1983).

[3] D. R. Strongin, and G. A. Somorjai; J. Catal. 109, 51 (1988)

[4] J.W. Geus; Appl. Catal. 25, 313 (1986).

[5] T. Hirano; Appl. Catal. 26, 65 (1986).

[6] T. Hirano; Appl. Catal. 28, 119 (1986).

[7] E.H. Lee; Catal. Rev. 8, 285(1973)

[8] M. Muhler, J. Schütze, M. Wesemann, T. Rayment, A. Dent, R. Schlögl, and G. Ertl; J. Catal. 126, 339 (1990).

[9] M. Muhler, R. Schlögl and G. Ertl; J. Catal. 138, 413 (1992).

[10] Th. Schedel-Niedrig, W. Weiss, and R. Schlögl; Phys. Rev. B 52, 17449(1995).

[11] M. Ritter, W. Ranke and W. Weiss; Phys. Rev. B 57, 7240 (1998).

[12] W. Weiss and M. Ritter; Phys. Rev. B 59, 5201 (1999).

[13] M. Ritter and W. Weiss; Surf. Sci. 432, 81 (1999). 
[14] V. V: Roddatis, D. S. Su, C. Kuhrs, W. Ranke, and R. Schlögl; Thin Solid Films , accepted (2001).

[15] Sh. K. Shaikhutdinov, Y. Joseph, C. Kuhrs, W. Ranke and W. Weiss; Farad. Disc. 114, 363 (1999).

[16] C. Kuhrs; PhD Thesis, FU Berlin (2000)

[17] Sh. K. Shaikhutdinov, W. Weiss, and R. Schlögl; Appl. Surf. Sci. 161, 497 (2000).

[18] Inorganic Crystal Structure Database; 12, (1999).

[19] J. Koehler and W. Urland, J. Sol. State Chem. 124, 169 (1996).

[20] I. Eliezer and R. A. Howard, High Temp. Sci. 10, 1 (1978).

[21] G. Eriksson, P. Wu, and A. D. Pelton, Calphad 17, 189 (1993)

[22] V. Ganesan and H. U. Borgstedt, J. Less-Comm. Met. 114343 (1985).

N. V. Dvoretskii, E. G. Stepanov, T. N. Sudzilovskaya, G. R. Kotelnikov, and V. V: Yun, Inorg. Mater. 25, 242 (1989)

G. Ketteler, W. Weiss, W. Ranke, and R. Schlögl; Phys. Chem. Chem. Phys. 3, 1114 (2001).

T. Takahashi, K. Kuwabara, and Y. Kase, Denki Kagaku 43, 273 (1975).

C. J. M. Rooymans, C. Langereis, and J. A. Schulkes, Sol. State Comm. 4, 85 (1965).

C. K. Kuo, Y. M. Yan, and P. S. Nicholson, Sol. State Ionics 92,45 (1996).

N. V. Dvoretskii, E. G. Stepanov, and Y. Yun, Inorg. Mater. 27, 1064 (1991).

EQUITHERM, Version 3.0, VCH Sientific Software; VCH Verlagsgesellschaft, Weinheim, (1993)

I. Barin; Thermochemical Data of Pure Substances, VCH, Weinheim, (1992).

W. Weiss, M. Ritter, D. Zscherpel, M. Swoboda and R. Schlögl; J. Vac. Sci. \& Technol. A 16, 21 (1998).

J. F. Moulder, W. F. Stickle, P. E. Sobol, and K. D. Bomben; Handbook of X-ray Photoelectron Spectroscopy, J. Chastain (Ed. ).

Perkin Elmer Cooperation, Eden Prairie, Minnesota, USA,(1992)

W. Ranke, M. Ritter, and W. Weiss; Phys. Rev. B 60, 1527 (1999).

Sh.K. Shaikhutdinov and W. Weiss; Surf. Sci. 432, L627 (1999).

S. J. Roosendaal, B. van Asselen, J. W. Elsenaar, A. M. Vredenberg, and F. H. P. M. Habraken; Surf. Sci. 442, 329 (1999).

M. P. Seah and W. A. Dench; Surface and Interface Analysis 1, 2 (1979).

K. Wandelt; Surf. Sci. Rep. 2, 1 (1982).

C.R. Brundle, T.J. Chuang, and K. Wandelt; Surface Science 68, 459 (1977).

S. B. Lee, M. Weiss, and G. Ertl; Surf. Sci. 108, 257 (1981).

H. H. Huang, X. Jiang, Z. Zou, and G. Q. Xu; Surf. Sci. 376, 245 (1997).

H. H. Huang, X. Jiang, Z. Zou, W. S. Chin, G. Q. Xu, W. L. Dai, K. N. Fan, and J. F. Deng; Surf. Sci. 412/413, 555 (1998).

H.-P. Bonzel, G. Pirug, and A. Winkler; Surf. Sci. 175, 287 (1986).

H. P. Bonzel and H. J. Krebs; in Physics and Chemistry of Alkali Metal Adsorption H. - P. Bonzel , A. M. Bradshaw and G. Ertl (ED. ) Elsevier Science Publishers B. V. (1989).

[44] C. Puglia, P. Bennich, J. Haselström, P. A. Brühwiler, A. Nilsson, A. J. Maxwell, N. Martenson, and P. Rudolf; Surf. Sci. 383, 149 (1997).

[45] A. F. Carley, S. D. Jackson, J. N. O'Shea, and M. W. Roberts; Surf. Sci. 440, L868 (1999).

[46] B. Lamontagne, F. Semond, and D. Roy; Surf. Sci. 327, 371 (1995).

[47] J. X. Wu, M. S. Ma, H. G. Zheng, H. W. Yang, J. S. Zhu, and M. R. Ji; Phys. Rev. B 60, 17102 (1999).

[48] J. Jupille, P. Dolle, and M. Besancon; Surf. Sci. 260, 271 (1992).

[49] A. Caballero, J. P. Espinos, A. Fernandez, L. Soriano, and A. R. Gonzalez-Elipe; Surf. Sci. 364, 253 (1996).

[50] A. Kotarba; private communication.

[51] C. Kuhrs, Y. Arita, W. Weiss, W. Ranke, and R. Schlögl; Topics in Catalysis 14, 111 (2001). 